\title{
Preliminary Comparison of Subcortical Structures in Elderly Subclinical Depression: Structural Analysis with 3T MRI
}

\author{
SangJin $\operatorname{Im}^{1}$, Jeonghwan Lee ${ }^{2}$ and Siekyeong Kim ${ }^{2 *}$ \\ ${ }^{1}$ Lee Gil Ya Cancer \& Diabetes Institute, Gachon University, Incheon 21999, \\ ${ }^{2}$ Department of Psychiatry, Chungbuk National University College of Medicine, Cheongju 28644, Korea
}

\begin{abstract}
Depression in the elderly population has shown increased likelihood of neurological disorders due to structural changes in the subcortical area. However, further investigation into depression related subcortical changes is needed due to mismatches in structural analysis results between studies as well as scarcities in research regarding subcortical connectivity patterns of subclinical depression populations. This study aims to investigate structural differences in subcortical regions of aged participants with subclinical depression using 3Tesla MRI. In structural analysis, volumes of each subcortical region were measured to observe the volumetric difference and asymmetry between groups, but no significant difference was found. In addition, fractional anisotropy (FA) and apparent diffusion coefficient (ADC) did not show any significant differences between groups. Structural analysis using probabilistic tractography indicated that the connection strength between left nucleus accumbens-right hippocampus, and right thalamus-right caudate was higher in the control group than the subclinical depression group. The differences in subcortical connection strength of subclinical depression groups, have shown to correlate with emotional and cognitive disorders, such as anxiety and memory impairment. We believe that the analysis of structural differences and cross-regional network measures in subcortical structures can help identify neurophysiological changes occurring in subclinical depression.
\end{abstract}

Key words: Subclinical depression, Brain, Basal ganglia, Volumetric, Diffusion tensor imaging, Tractography

\section{INTRODUCTION}

The human body becomes vulnerable to various diseases with age, as its biological structure and function decline. One part of the body notably affected by age is the brain where its function gradually decreases, leading to increased vulnerability to mental illnesses and diseases such as cerebrovascular disease and metabolic brain disease [1]. An aging brain typically shows various structural volume changes that correlate with the formation of brain diseases [2]. Mental illness of seniors can be caused by various factors such as psychological attitudes, socioeconomic conditions, adaptation

Submitted November 29, 2020, Revised January 19, 2021 ,

Accepted February 17,2021

* To whom correspondence should be addressed. TEL: 82-43-269-6364, FAX: 82-43-267-7951 e-mail:poshong@chungbuk.ac.kr difficulties due to changes in the environment, deterioration in physiology caused by aging, and other complex combinations of biological, mental, and social factors [3, 4]. Previous studies have shown an increasing trend of mental illness in aging seniors, with the most common diseases being dementia and depression $[5,6]$.

Subclinical depression (SD), a condition that does not meet the criteria for depressive disorder despite having depressive symptoms, is known to have a significant effect on the quality of life due to combination symptoms such as mild grief and numbness. Additionally, a previous study showed that the risk of developing minor depression from SD is increased in subjects with SD [7]. Therefore, early detection by biomarker testing for SD can help in early symptom detection and disease evaluation [8].

Research using magnetic resonance imaging (MRI) to identify changes in morphological and functional characteristics of the brain has improved the understanding of mental diseases [9]. Due to excellent contrast provided by MRI, it is possible to distinguish 
the gray matter (GM), the white matter (WM) and the cerebrospinal fluid (CSF) of the brain, and compare their relative size and shape differences in subcortical areas between subjects [10,11]. Changes in subcortical structures are related to various neurological disorders such as dementia and depression [12]. Using image data, it is possible to measure volume and cortical thickness of the entire brain or regions of interest (ROI). Image techniques such as Diffusion Tensor Image (DTI) enables structural analysis [13, 14] and tractography analysis of mapped neural connectivity by reconstructing each voxel containing diffusion information into a fiber path $[15,16]$. Such analyses can show various brain pathologies involved in changes in behavior, learning, and aging.

According to previous studies using MRI, the subcortical GM areas of patients with depression are mostly smaller when compared to those of normal subjects [17]. For example, areas such as nucleus accumbens, amygdala, caudate, hippocampus, globus pallidus, putamen and thalamus reported volume reduction in metaanalysis studies [18, 19]. In addition, as part of the limbic-corticalstriatal-pallidal-thalamic (LCSPT) subcortical network related to the pathophysiology of major depression disorder (MDD), the thalamus and hippocampus were previously associated with a dysfunctional subcortical-cortical intra-network [20]. Hippocampus in particular is known to play an important role in memoryrelated processing, and structural changes in this area have shown to correlate with emotional and cognitive disorders such as anxiety and depression [21-23]. Studies on the thalamus, an area known for processing emotions, have shown that iron deposits in thalamus can trigger depressive symptoms with age [24]. However, there are various inconsistencies between studies on subcortical changes regarding mood disorders [25,26].

It has been reported that the volumetric asymmetry of the left and right hemispheres affects cognitive and emotional function in brain structures [27]. The valence hypothesis reports that the right hemisphere is related to negative emotions and the left hemisphere is related to positive emotions [28]. A study using MRI reported reduced asymmetry in depressed patients using voxel-based morphometry (VBM) on ROIs [29]. However, there are few reports of depression related asymmetrical changes in subcortical structures [30].

Synaptic plasticity-related functional disorders, which can occur early in various neurophysiological pathologies, are shown to influence neurological psychopathic symptoms such as depression $[31,32]$. Previous studies using DTI found loss of WM fiber integrity in patients with depression and suggested that the connectivity differences in subcortical areas form the basis of several stages of depression [33]. The results of the study on WM microstructure damage in patients with depression suggest that the disruption of wide-spread fiber connectivity between brain structures can influence the flow of neurotransmitter materials and cause a chain reaction of imbalance in neurotransmitter concentration of connected brain structures [34-36]. However, inconsistency in the patterns of subcortical structural and connectivity analysis reported in each study suggests a need for further investigation. Additionally, since the physiological changes of SD participants are similar to that of participants with MDD, it will be helpful in understanding depression-related physiological changes of the brain.

This study provides a comprehensive cross-sectional analysis of characteristics in brain structures related to SD in two groups of elderly populations using 3T MRI. Based on previous studies that showed SD can develop into major depression disorder (MDD), we hypothesized that structural changes in the subcortical area that appear in MDD will also be seen in SD [7]. The subcortical areas, nucleus accumbens, amygdala, caudate, hippocampus, globus pallidus, putamen, and thalamus were divided into two hemispheres and measured quantitatively using MPRAGE and DTI data collected from participants in age between 65 to 83 . The results of this study can serve as a reference database for the study of depression-related brain connectivity.

\section{MATERIALS AND METHODS}

\section{Subject preparation}

The experiment was conducted by recruiting seniors over the age of 65 from the Senior Welfare Center in Cheongju, North Chungcheongbuk-do. Seniors who agreed to participate were interviewed with a psychiatrist using the Structured Clinical Interview of DSM-IV (SCID) [37]. A total of 39 participants were recruited with no signs of major depressive disorder at the time of study participation. All participants underwent Short Brief Michigan Alcoholism Screening Test-Geriatric version (SMAST-G) for screening alcohol use disorder [38] and the Korean version of minimental status examination(MMSE-KC) [39] for assessing general cognitive function. Participants were divided into two groups (20 in the control and 19 in the SD group) based on scores of Korean version of the short geriatric depression scale (SGDS-K) [40]. The seniors that classified as the $\mathrm{SD}$ group received a score greater than or equal to 8 out of 15 in SGDS-K while the seniors that classified as control group scored less than 8 in SGDS-K. The basis for the SGDS-K score cutoff was based on the results of a previous study that suggested an optimal cutoff point for screening major depressive disorder (MDD) and minor depressive disorder (MnDD) in community-dwelling seniors as 8 points [41]. To assess the subject's language function and verbal memory, each subject took verbal fluency, Boston naming test, word list test in Korean version 
of CERAD (CERAD-K) [42]. Age, gender, years of education, and test scores of the subjects were calculated into standard scores $(\mathrm{z}$ score). All participants with a history of head trauma, neurological disease, substance use disorder and major psychiatric disorders such as schizophrenia or bipolar disorders were excluded. This study was approved by the Chungbuk National University Bioethics Review Committee.

\section{MR image acquisition}

Image data acquisition was conducted on a 3 Tesla Philips Achieve MRI scanner (Philips Medical System, Netherlands). For signal reception, a Sensitivity encoding (SENSE) 8-channel head coil was applied. The pulse sequence used for this acquisition was High-resolution T1-weighted three-dimensional magnetizationprepared rapid gradient echo (T1-MPRAGE) (Gradient echo sequence with a Repetition Time $(\mathrm{TR})=6.8 \mathrm{~ms}$, Echo Time $(\mathrm{TE})=3.2 \mathrm{~ms}$, Flip Angle $(\mathrm{FA})=9^{\circ}$, Bandwidth $=241.1 \mathrm{~Hz}$, Field Of View $(F O V)=256 \times 240 \mathrm{~mm}$, Slice Thickness $=1.2 \mathrm{~mm}$, Matrix size $=256 \times 240$, Voxel size $=1 \times 1 \times 1.2 \mathrm{~mm}^{3}$, Number of Slice $=170$, Scan time $=5 \mathrm{~m} 34 \mathrm{~s}$ ) and 2D EPI-Diffusion tensor (Spin echo sequence with a Repetition Time $(\mathrm{TR})=6,033 \mathrm{~ms}$, Echo Time $(\mathrm{TE})=70 \mathrm{~ms}$, Flip Angle $(\mathrm{FA})=90^{\circ}$, Bandwidth $=29.8 \mathrm{~Hz}$, Field Of View $(F O V)=224 \times 224 \mathrm{~mm}$, Matrix size $=112 \times 109$, Slice Thick ness $=3 \mathrm{~mm}$, Voxel size $=2 \times 2.04 \times 3 \mathrm{~mm}^{3}$, Number of Slice $=50$, Diffusion gradient pulse duration $(\delta)=34.4 \mathrm{~ms}$, Diffusion gradient separation $(\Delta)=12.3 \mathrm{~ms}, \mathrm{~B}$-value $=1,000 \mathrm{~s} / \mathrm{mm}^{2}$, Scan time $=3 \mathrm{~m} 31$ s). Acquired image data are shown in Fig. 1.

\section{Image data processing}

Pipelines used for image data analysis used software libraries such as FMRIB software library version 5.0.1 (FSL, Created by the Analysis Group, Oxford, UK) [43, 44] and MRtrix3 (Brain Research Institute, Melbourne, Australia) [45]. First, all DICOM data were converted to NIFTI format, then had the brains extracted from the skulls of each converted NIFTI data. After registering each extracted brain image to Montreal Neurological Institute (MNI) 152 space, brain volumes were segmented to calculate the total brain tissue volume [46-48]. Second, using the FIRST tool, we extracted subcortical regions (Nucleus Accumbens, Amygdala, Caudate, Hippocampus, Globus Pallidus, Putamen, and Thalamus) from the registered images and measured their volume [49]. Lastly, we performed eddy correction using FSL's eddy then generated fiber reconstruction data using FSL's BEDPOSTX [50] and probabilistic tractography data using FSL's PROBTRACKX [51]. The image processing pipeline used in this study is shown in Fig. 2.

\section{Volumetric analysis}

Segmentation of nucleus accumbens, amygdala, caudate, hippocampus, globus pallidus, putamen, and thalamus, was performed using FMRIB software library version 5.0.1 (FSL, Created by the Analysis Group, Oxford, UK) on acquired MPRAGE data. The volume of segmented structures was measured using FSL's fslstats. All segmentations were divided into left and right hemispheres and used to evaluate the left and right hemisphere asymmetry in the subcortical area. The raw volumes of the measured subcortical areas were adjusted for individual differences in brain size before intergroup comparisons was compared between groups to account [52]. Intergroup comparisons were then performed by correcting for individual differences in brain size.

\section{Probabilistic tractography analysis}

DTI data obtained for probabilistic tractography analysis were denoised using MRtrix3 [53]. Eddy currents, susceptibility induced distortions and subject motion were corrected using FSL's eddy. The preprocessed data was fitted with a diffusion tensor model using the DTIFIT function to obtain a scalar DTI map

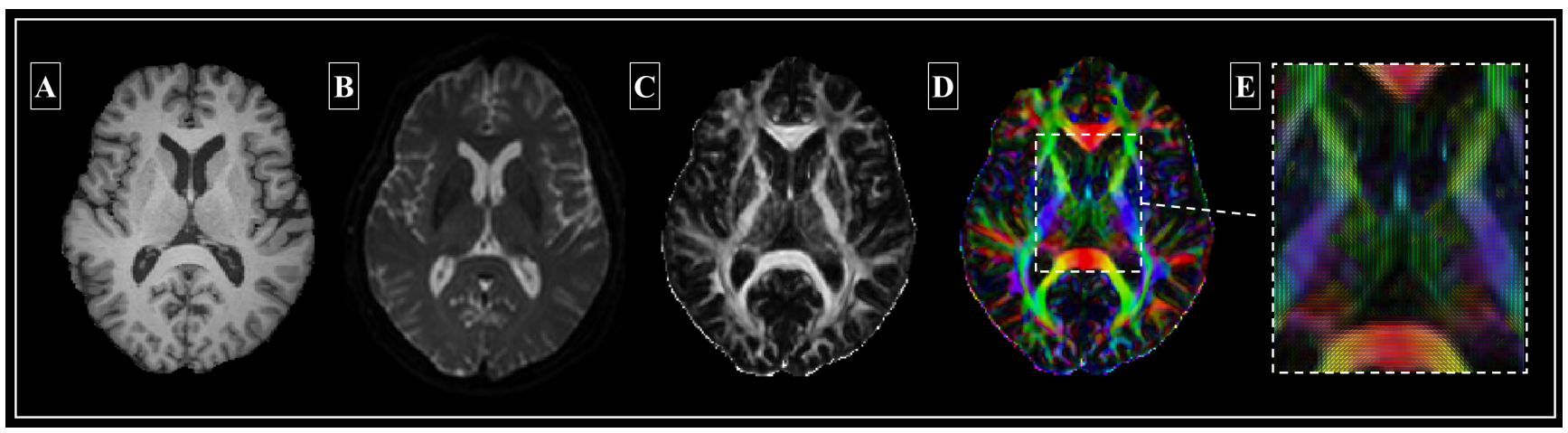

Fig. 1. Acquired image data (coronal plane) and the processed results using FSL. MPRAGE (A), DTI (B), FA map (C), FA color map (D), example of fiber orientation produced in each voxel. 


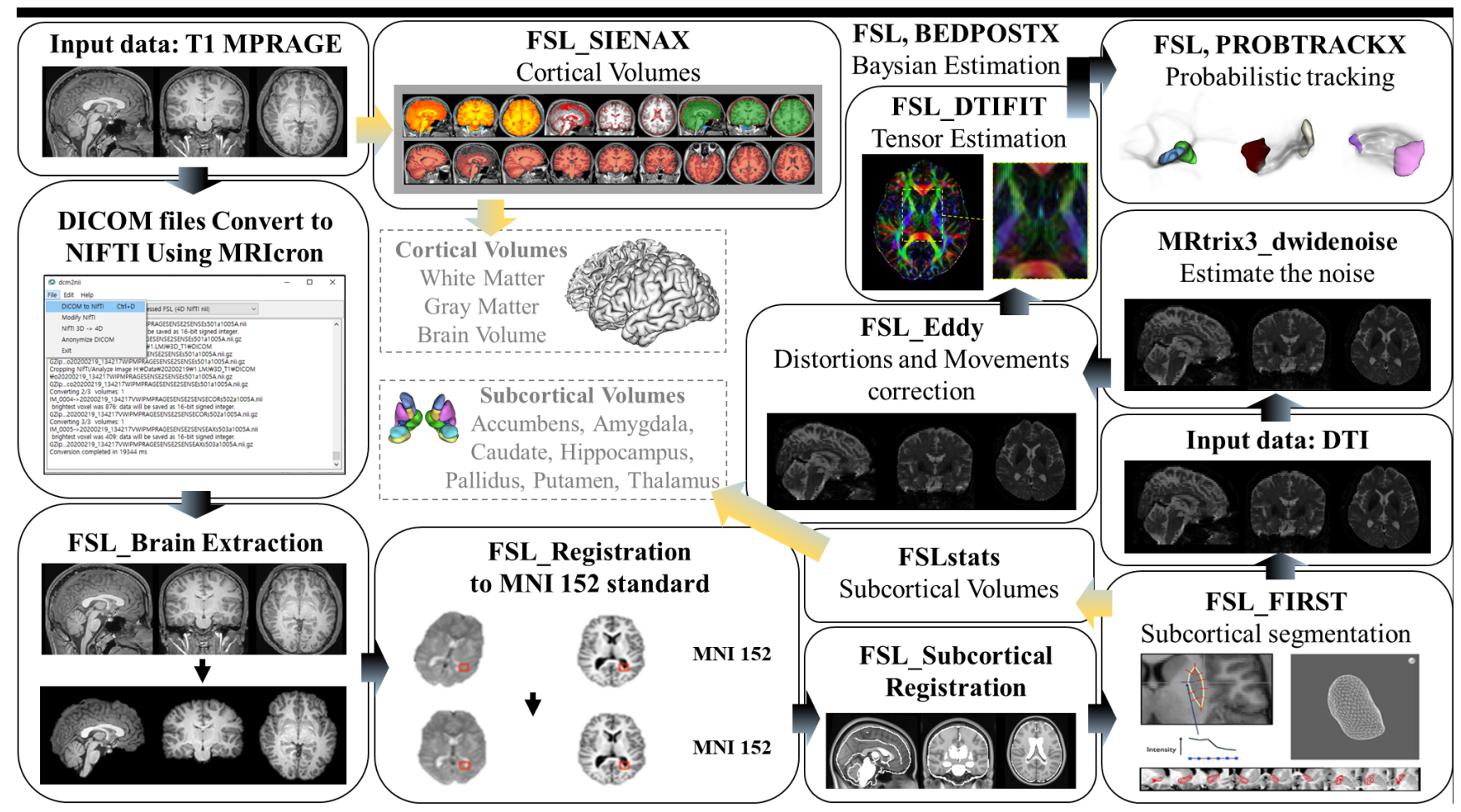

Fig. 2. Full analysis pipeline of the image data.

and fiber orientation information. Results of DTIFIT was used to measure fractional anisotropy (FA) and apparent diffusion coefficient (ADC) through the fslmaths function. BEDPOSTX was performed to construct the distribution for the diffusion parameters in each voxel using Markov Chain Monte Carlo sampling. The detailed options were 3 number of fibers per voxel, 3000 burnin period, zeppelins model. PROBTRACKX was performed using the BEDPOSTX results and the segmented brain structure region mask. In PROBTRACKX each structure is designated as a seed and target, and the number of streamlines passing through the target structure and the shape of the streamline are simulated by probabilistic tractography results. The detailed options were 5000 samples per voxel, curvature threshold of 0.2 and step size of 1 .

Tractography results were sorted by seed, normalized using the volume of individual brain structures of all subjects, and then averaged. The left and right hemisphere connectivity information were displayed in matrix form by converting it to a $\log 10$ scale. The matrix represents the connectivity between all divided structures, and presented in a total of 4 quadrants in the form of left hemisphere-left hemisphere, left hemisphere-right hemisphere, right hemisphere-left hemisphere and right hemisphere-right hemisphere [54].

\section{Statistical analysis}

For statistical analysis, independent sample t-tests and Pearson correlation coefficient were performed using Statistical Package for the Social Sciences software (SPSS version 23, IBM Corporation, New York). Correction for the differences in the individual's head size was done with the spinning equation [55].

$$
\mathrm{V}_{\text {standard }}=\frac{V_{r o i}}{V_{N B V}} \times 10^{6}
$$

Vroi is each subcortical volume, VNBV is normalized brain volume (NBV), and Vstandard is standardized volume corrected according to NBV.

The following equation was used to find the asymmetric size of the subcortical region [56,57].

$$
A I=\frac{|(L-R)|}{(L+R)} \times 100
$$

$\mathrm{AI}$ is the Asymmetry Index, $\mathrm{L}$ is the structure of the left hemisphere, and $\mathrm{R}$ is the structure of the right hemisphere.

AI represents a decrease in the degree of asymmetry in a specific structure, and when the values of the left and right structures are the same, AI indicates zero. AI represents asymmetry measurement in a form of a percentage that does not point towards a specific hemisphere. 
The differences in the result of the neuropsychological test within the subcortical regions were statistically tested using $\mathrm{z}^{-}$ transformed correlations with the independent t-test. The arithmetic formula of $\mathrm{z}$-score is as follows.

$$
Z=\frac{(X-\mu)}{\sigma}
$$

$\mathrm{X}$ is the random variable, $\mu$ is the mean of the random variable $\mathrm{X}$, and $\sigma$ is the standard deviation.

Volume differences of neuropsychological test results effect size (Cohen's d) were calculated between the Control group and the SD group. The arithmetic formula of effect size (Cohen's d) is as follows.

$$
\text { Cohen`s d }=\frac{(M 2-M 1)}{S D_{\text {Pooled }}}
$$

M1 and M2 are the means of the structural volume of the Control and SD group, respectively, and $\mathrm{SD}_{\text {pooled }}$ is the standard deviation. Cohen's $\mathrm{d}$ is the smallest in the range from 0.2 to 0.4 , moderate between 0.5 to 0.7 , and the biggest above 0.8 .

All image data were tested for normality through shapiro-wilk test, and equal variance test was performed through levene's test of independent t-test. Independent t-tests evaluated the differences normalized volume, asymmetry index, and pathways between the control group and the SD group. Demographic differences between groups were assessed using chi-square test (e.g. sex) and Independent t-test (e.g. age and education level). Additionally, the correlation of SGDS-K, MMSE-KC, SMAST-G and neuropsychological function between each group and the correlation between each pathway and neuropsychological function were assessed through Pearson correlation. In addition, we used false discovery rate (FDR) to correct for false positives [58]. Since the FDR correction can overlook potentially important results using a strict FDR

Table 1. Demographical statistics of each participant

\begin{tabular}{llcccc}
\hline & Unit & $\begin{array}{c}\text { Control } \\
\text { group } \\
\text { mean } \pm \text { SD } \\
\mathbf{n}=\mathbf{2 0}\end{array}$ & $\begin{array}{c}\text { SN group } \\
\text { mean } \pm \text { SD } \\
\mathbf{n}=\mathbf{1 9}\end{array}$ & $\begin{array}{c}\text { Total } \\
\text { mean } \pm \text { SD } \\
\mathbf{n}=\mathbf{3 9}\end{array}$ & $\begin{array}{c}\text { Analysis } \\
\chi^{\mathbf{2}} \\
\text { (p-value) }\end{array}$ \\
\hline Sex & $\begin{array}{l}\text { Male } \\
\text { Female }\end{array}$ & 6 & 6 & 12 & $0.345(0.557)$ \\
& & 13 & 14 & 27 & \\
\hline Age & Year & $69.58 \pm 4.51$ & $72.20 \pm 4.53$ & $70.89 \pm 4.52$ & $-1.573(0.124)$ \\
EDU & Year & $10.89 \pm 3.93$ & $10.00 \pm 4.08$ & $10.45 \pm 4.00$ & $0.698(0.490)$ \\
\hline
\end{tabular}

Significant p-value displayed in bold.

Data given in mean \pm standard deviation $(\mathrm{SD})$.

EDU, Education. cutoff, a relatively acceptable cutoff of 0.2 was established $[59,60]$. The application of FDR was performed based on Seed volume, FA, ADC, and connectivity values of each structural region corresponding to each table, and in correlation with the results of neuropsychological tests. FDR correction was applied to volume, FA, $\mathrm{ADC}$, and asymmetry, respectively, and the connection pathways representing the connectivity between two structures were divided into left and right hemispheres.

\section{RESULTS}

\section{Demographic and psychological characteristics of the subjects}

In this study, demographic characteristics were compared between recruited seniors in the control and SD group using chi square test and Independent t-test. The average age between the controls and SD group was $69.58 \pm 4.51,72.20 \pm 4.53$, respectively, with no significant difference in age (p: 0.124). Additionally, the sex ratio was higher for women (Control group (N): 13, SD group $(\mathrm{N})$ : 14) than men (Control group $(\mathrm{N})$ : 7, SD group $(\mathrm{N})$ : 5), but had no significant difference (p: 0.557). In addition, the level of education evaluated by training was $10.89 \pm 3.93$ (control group) and 10.00 \pm 4.08 (SD group) for each group, showing no significant difference (p: 0.490). The chi square test and independent t-test results are shown in Table 1.

The correlation between the two groups and neuropsychologi-

Table 2. Neuropsychological testing scores of each participant

\begin{tabular}{lcccc}
\hline $\begin{array}{c}\text { Word list } \\
\text { test }\end{array}$ & $\begin{array}{c}\text { Control } \\
\text { group } \\
\text { mean } \pm \text { SD } \\
\mathbf{n = 2 0}\end{array}$ & $\begin{array}{c}\text { SN group } \\
\text { mean } \pm \text { SD } \\
\mathbf{n = 1 9}\end{array}$ & $\begin{array}{c}\text { Total } \\
\text { mean } \pm \text { SD } \\
\mathbf{n = 3 9}\end{array}$ & $\mathbf{t}$ \\
\hline GDS-KC & $2.21 \pm 2.27$ & $10.40 \pm 2.04$ & $6.31 \pm 2.16$ & $.890^{* * *}$ \\
MMSE-KC & $28.58 \pm 0.77$ & $27.90 \pm 1.33$ & $28.24 \pm 1.05$ & -.303 \\
SMAST-G & $0.47 \pm 1.43$ & $1.25 \pm 1.65$ & $0.86 \pm 1.54$ & .249 \\
Memory_z & $0.73 \pm 0.84$ & $0.34 \pm 0.69$ & $0.54 \pm 0.76$ & -.254 \\
Recall_z & $0.23 \pm 0.88$ & $-0.42 \pm 0.72$ & $-0.10 \pm 0.80$ & $-.384^{*}$ \\
Recognition_Z & $0.48 \pm 0.33$ & $-0.54 \pm 0.86$ & $-0.03 \pm 0.59$ & $-.623^{* * *}$ \\
Boston_z & $0.61 \pm 0.62$ & $0.49 \pm 0.91$ & $0.55 \pm 0.76$ & -.075 \\
Fluency_z & $0.41 \pm 1.08$ & $-0.27 \pm 0.80$ & $0.07 \pm 0.94$ & $-.343^{*}$ \\
\hline
\end{tabular}

${ }^{*} \mathrm{p}<.05,{ }^{* *} \mathrm{p}<.01,{ }^{* * *} \mathrm{p}<.001$ by Significance of correlation $(\mathrm{p} \leq 0.05)$.

Data given in mean \pm standard deviation $(\mathrm{SD})$.

SGDS-K: Korean version of short Geriatric Depression Scale.

MMSE-KC: Mini Mental Status Examination in the Korean version of the CERAD assessment packet.

SMAST-G: Short Brief Michigan Alcoholism Screening Test-Geriatric version.

Memory, Word list memory; Recall, Word list Recall; Recognition, Word list Recognition; BNT, Boston naming test; VF, Verbal fluency test; z, Zscore. 


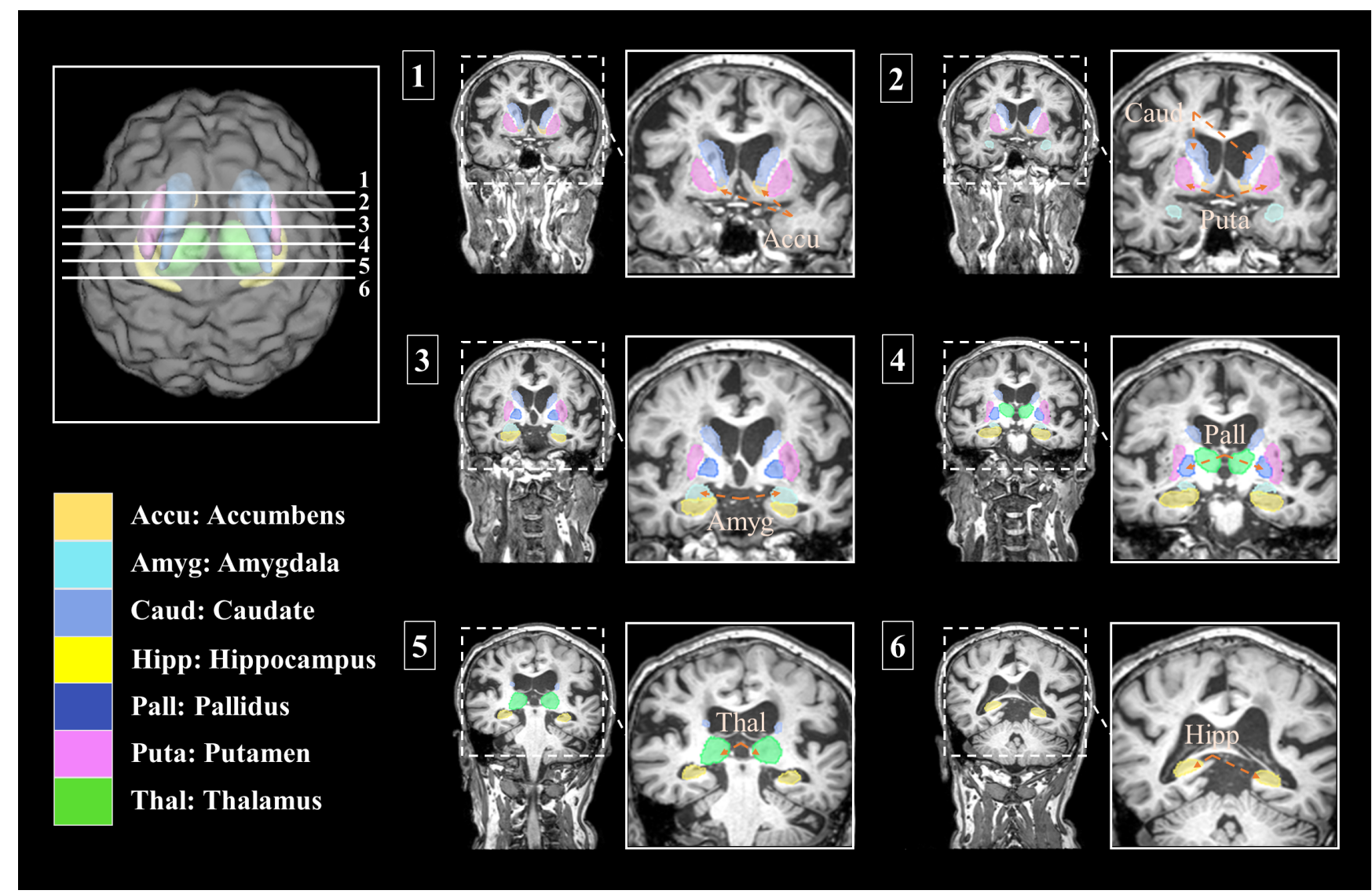

Fig. 3. The segmentation result of subcortical structures from the entire brain. 3D rendered brain are shown with the slice number to match the location of the subcortical structures (Top left), subcortical structure label (Bottom left), segmentation of the subcortical structures overlaid on MPRAGE image data (Right 1 6).

cal testing scores was confirmed by Pearson correlation in Table 2. In the SGDS-KC test, the SD group showed a higher score and showed a significant correlation ( $\mathrm{p}:<0.001$ ). The comparison results of word list recall (p: 0.016), word list recognition (p: $<0.001$ ), and verbal fluency test (p: 0.032) were significantly lower in the SD group. however, scores of MMSE-KC (p: 0.061), SAMST-G (p: 0.126 ), Word list memory (p: 0.119), and Boston naming tests ( $\mathrm{p}$ : 0.648 ) showed no significant correlation.

\section{Segmentation of brain subcortical structure}

Brain segmentation analysis was performed on MPRAGE images using FSL, with the segmented subcortical areas presented in Fig. 3. The segmented subcortical regions are all divided into left and right hemispheric areas and visualized on the extracted brain from the MPRAGE images to accurately quantify the segmentation of nucleus accumbens, amygdala, caudate, hippocampus, globus pallidus, putamen, and thalamus. The visualized subcortical areas are presented in Fig. 3, and detailed positions and shapes of them are identified on each slide. Also, the segmentation results are
3D rendered in Fig. 4.

\section{Quantitative morphometric analysis of the subcortical structure}

The $\mathrm{p}$-value of independent t-tests on significant differences of subcortical volumes and FDR corrected results are displayed in Table 3. The results of the comparisons between mean subcortical volumes between the two groups are as follows. The control groups left hemisphere volumes were greater than the SD groups volumes in the nucleus accumbens (Left: -3.4\%, p: 0.679), amygdala (Left: $-4.7 \%$, p: 0.673 ), caudate (Left: $-10.1 \%$, p: 0.158), hippocampus (Left: -3.9\%, p: 0.539), globus pallidus (Left: - 19.4\%, p: 0.176), putamen (Left: $-2.5 \%$, p: 0.693 ) and thalamus (Left: $-1.3 \%$, p: 0.738). In the left hemisphere, globus pallidus showed the biggest gap, and thalamus showed the smallest difference. The control group's right hemisphere volumes were greater than the SD group's volumes in the nucleus accumbens (Right: -12.3\%, p: 0.057), amygdala (Right: 7.2\%, p: 0.399), caudate (Right: 0.6\%, p: 0.948), hippocampus (Right: 0.1\%, p: 0.985), globus pallidus (Right: $-1.0 \%$, p: 0.953), 


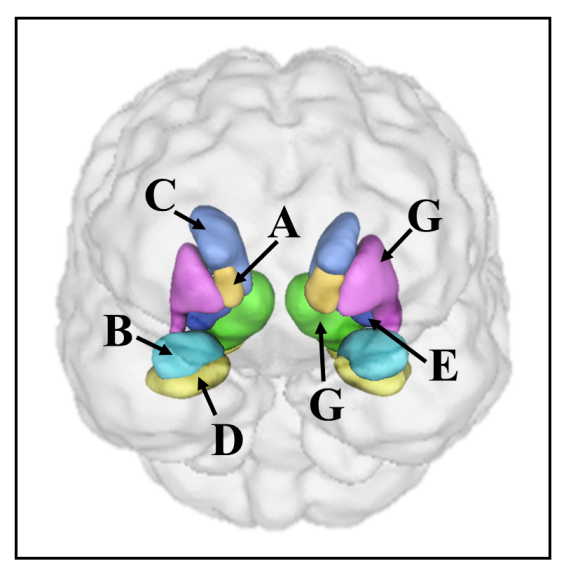

A

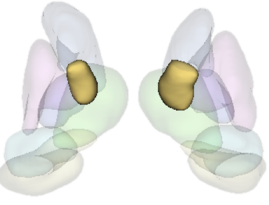

B

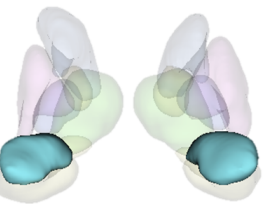

C

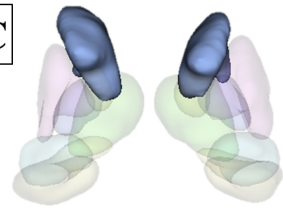

D

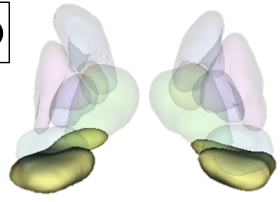

E

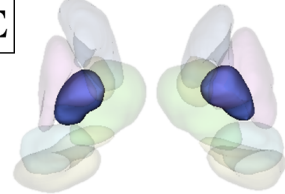

$\mathbf{F}$

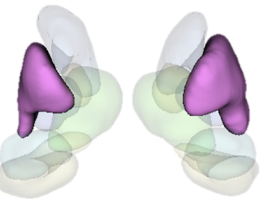

G
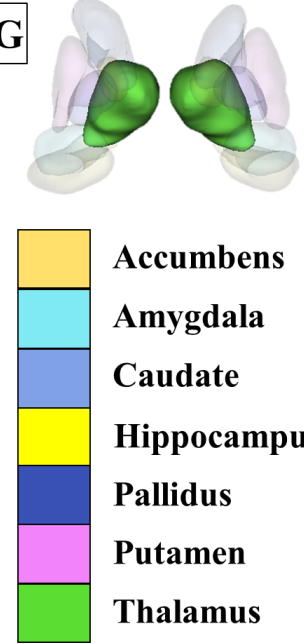

Accumbens

Amygdala

Caudate

Hippocampus

Pallidus

Putamen

Thalamus

Fig. 4. Segmented subcortical structures rendered in 3D. Model Plot of the position of subcortical areas (Left), location indicator and the label information of each subcortical structures (Right A F).

Table 3. Volume measurements of subcortical structures for control and SD group

\begin{tabular}{llcccccc} 
& \multicolumn{5}{c}{ Nomalized volume } \\
& ROI & $\begin{array}{c}\text { Control group } \\
\text { mean } \pm \text { SD } \\
\mathbf{n = 1 9}\end{array}$ & $\begin{array}{c}\text { SN group } \\
\text { mean } \pm \text { SD } \\
\mathbf{n = 2 0}\end{array}$ & $\begin{array}{c}\text { Absolute } \\
\text { difference } \\
\left(\mathbf{m m}^{3}\right)\end{array}$ & $\begin{array}{c}\text { Percentage } \\
\text { difference } \\
\mathbf{( \% )}\end{array}$ & $\begin{array}{c}\text { Cohen's d } \\
\text { p-value } \\
\text { (FDR) }\end{array}$ \\
\hline Left & Accumbens & $266.822 \pm 78.302$ & $257.768 \pm 54.497$ & 9.054 & -3.4 & 0.134 & $0.679(0.939)$ \\
& Amygdala & $699.550 \pm 195.739$ & $666.663 \pm 281.424$ & 32.887 & -4.7 & 0.136 & $0.673(0.939)$ \\
& Caudate & $2,150.217 \pm 352.776$ & $1,933.213 \pm 555.041$ & 217.004 & -10.1 & 0.467 & $0.158(0.821)$ \\
& Hippocampus & $2,745.636 \pm 434.846$ & $2,639.871 \pm 618.219$ & 105.765 & -3.9 & 0.198 & $0.539(0.939)$ \\
& Pallidus & $2,218.900 \pm 1,038.884$ & $1,789.036 \pm 898.619$ & 429.864 & -19.4 & 0.443 & $0.176(0.821)$ \\
& Putamen & $826.835 \pm 180.521$ & $806.347 \pm 137.257$ & 20.488 & -2.5 & 0.128 & $0.693(0.939)$ \\
& Thalaus & $2,813.585 \pm 345.487$ & $2,776.754 \pm 336.720$ & 36.831 & -1.3 & 0.108 & $0.738(0.939)$ \\
Right & Accumbens & $187.855 \pm 44.153$ & $164.726 \pm 26.650$ & 23.129 & -12.3 & 0.634 & $0.057(0.798)$ \\
& Amygdala & $642.576 \pm 146.277$ & $688.665 \pm 189.147$ & 46.089 & 7.2 & -0.273 & $0.399(0.939)$ \\
& Caudate & $2,056.552 \pm 499.238$ & $2,068.496 \pm 623.965$ & 11.944 & 0.6 & -0.021 & $0.948(0.985)$ \\
& Hippocampus & $2,793.791 \pm 488.173$ & $2,796.716 \pm 444.167$ & 2.925 & 0.1 & -0.006 & $0.985(0.985)$ \\
& Pallidus & $1,465.499 \pm 765.667$ & $1,451.172 \pm 740.233$ & 14.327 & -1.0 & 0.019 & $0.953(0.939)$ \\
& Putamen & $745.986 \pm 131.817$ & $765.615 \pm 132.065$ & 19.629 & 2.6 & -0.149 & $0.645(0.985)$ \\
& Thalaus & $2,882.897 \pm 342.515$ & $2,789.203 \pm 318.472$ & 93.694 & -3.2 & 0.283 & $0.383(0.939)$ \\
\hline
\end{tabular}

Data given in mean \pm standard deviation $(\mathrm{SD})$.

Volume is measured in cubic units $\left(1\right.$ voxel $\left.=1 \mathrm{~mm}^{3}\right)$.

Significant $\mathrm{p}$-value displayed in italics $(\mathrm{p} \leq 0.05)$.

Among the $\mathrm{p}$-values showing significant differences, the values that passed the FDR correction $(\mathrm{p} \leq 0.2)$ are displayed in bold.

putamen (Right: $2.6 \%$, p: 0.645 ) and thalamus (Right: $-3.2 \%$, p: 0.383). Furthermore, in the right hemisphere, nucleus accumbens showed the largest difference, while the hippocampus showed the smallest difference. Overall, volumetric comparison between the left and right hemispheres showed that most subcortical volumes were greater in the Control group than subcortical volumes of the SD group, as shown in Table 3, and that the left hemisphere volumes were larger than the right volumes. However, there was no significant difference between groups in both the left and right hemisphere subcortical volumes (FDR $p>0.2$ ). Since the differences of flat volumetric changes (pre-normalized values corrected for brain size) must be considered, a raw volume analysis of each group's subcortical area was performed to show similar increases and decreases as shown in Table 3. Comparison of raw volumes of subcortical regions between groups is presented in Supplementary Table 1. 
Table 4 shows the volumetric asymmetry of all subcortical regions of the control group and SD group. In the Control group, volumetric asymmetry was larger in globus pallidus (p: 0.172), putamen (p: 0.448), thalamus (p: 0.277), and caudate (p: 0.167), whereas, in the SD group, volumetric asymmetry was larger in the nucleus accumbens (p: 0.127), hippocampus (p: 0.488), and amygdala (p: 0.221). However, none of the volumetric asymmetries was significantly different between groups (FDR p $>0.2$ ).

Table 4. The arithmetic means of asymmetry index of subcortical structures in Control and SD group

\begin{tabular}{lccc}
\hline \multirow{3}{*}{ ROI } & $\begin{array}{c}\text { Control group } \\
\text { mean } \pm \text { SD } \\
\mathbf{n}=\mathbf{2 0}\end{array}$ & $\begin{array}{c}\text { SD group } \\
\text { mean } \pm \text { SD } \\
\mathbf{n}=\mathbf{1 9}\end{array}$ & $\begin{array}{c}\text { p-value } \\
\text { (FDR) }\end{array}$ \\
\hline Accumbens & $16.446 \pm 11.008$ & $21.445 \pm 8.771$ & $0.127(0.387)$ \\
Amygdala & $3.474 \pm 15.596$ & $3.634 \pm 19.913$ & $0.221(0.387)$ \\
Caudate & $3.122 \pm 8.600$ & $2.965 \pm 17.190$ & $0.167(0.387)$ \\
Hippocampus & $0.820 \pm 10.455$ & $3.621 \pm 14.284$ & $0.488(0.488)$ \\
Pallidus & $20.116 \pm 23.883$ & $9.803 \pm 22.249$ & $0.172(0.387)$ \\
Putamen & $4.675 \pm 9.173$ & $2.704 \pm 6.587$ & $0.448(0.488)$ \\
Thalamus & $1.225 \pm 3.103$ & $0.258 \pm 2.287$ & $0.277(0.388)$ \\
\hline
\end{tabular}

Data given in mean \pm standard deviation $(\mathrm{SD})$.

Significant $\mathrm{p}$-value displayed in italics $(\mathrm{p} \leq 0.05)$.

Among the $\mathrm{p}$-values showing significant differences, the values that passed the FDR correction $(\mathrm{p} \leq 0.2)$ are displayed in bold.
Table 5 shows the statistical difference of all average FA and ADC values between the control and SD groups. Although there were no significant differences in the FA values between the two groups, ADC value on the left hippocampus area was significantly different (p: 0.047). However, after FDR correction was done, the significant difference disappeared (FDR $\mathrm{p}>0.2$ ).

\section{Comparison of probabilistic tractography analysis}

Probabilistic tractography was used to compare the subcortical connectivity between the SD group and the Control group. The results of probabilistic tractography analysis, which involves a Ttest comparison of each group's connectivity, are presented in the form of a linked matrix (Fig. 5). The subcortical connectivity map is a scale-color map, with seven left and right anatomical detail areas, estimating the connectivity between a total of 14 areas. A total of 39 matrix maps (Control group (N): 20, SD group (N): 19) was created using the acquired DTI data of all groups. Matrix maps of SD and control groups were averaged to compare and analyze the intergroup connectivity matrix maps. The connectivity values between the subcortical structures of SD and control groups are shown in Supplementary Table 2. Each matrix shows the connectivity between the left column as the seed area and the top row as the target area. The estimates between seed and target area are not necessarily the same as connectivity estimates between target and seed areas due to fibers being generated from one region. Further-

Table 5. FA and ADC of subcortical structures for Control and SD group

\begin{tabular}{|c|c|c|c|c|c|c|c|}
\hline & \multirow[b]{2}{*}{ ROI } & \multicolumn{3}{|c|}{ FA } & \multicolumn{3}{|c|}{ ADC } \\
\hline & & $\begin{array}{c}\text { Control group } \\
\text { mean } \pm \text { SD } \\
n=19\end{array}$ & $\begin{array}{c}\text { SN group } \\
\text { mean } \pm S D \\
n=20\end{array}$ & $\begin{array}{c}\text { p-value } \\
\text { (FDR) }\end{array}$ & $\begin{array}{c}\text { Control } \\
\text { mean } \pm S D \\
n=19\end{array}$ & $\begin{array}{c}\text { Depression } \\
\text { mean } \pm S D \\
n=20\end{array}$ & $\begin{array}{l}\text { p-value } \\
\text { (FDR) }\end{array}$ \\
\hline \multirow[t]{7}{*}{ Left } & Accumbens & $2.262 \mathrm{E}-1 \pm 2.841 \mathrm{E}-2$ & $2.297 \mathrm{E}-1 \pm 2.762 \mathrm{E}-2$ & $0.696(0.986)$ & $7.320 \mathrm{E}-4 \pm 4.444 \mathrm{E}-5$ & $7.105 \mathrm{E}-4 \pm 5.250 \mathrm{E}-5$ & $0.176(0.543)$ \\
\hline & Amygdala & $2.185 \mathrm{E}-1 \pm 3.639 \mathrm{E}-2$ & $2.290 \mathrm{E}-1 \pm 3.801 \mathrm{E}-2$ & $0.387(0.986)$ & $8.333 \mathrm{E}-4 \pm 3.516 \mathrm{E}-5$ & $8.617 \mathrm{E}-4 \pm 8.589 \mathrm{E}-5$ & $0.194(0.543)$ \\
\hline & Caudate & $3.920 \mathrm{E}-1 \pm 5.082 \mathrm{E}-2$ & $4.077 \mathrm{E}-1 \pm 3.256 \mathrm{E}-2$ & $0.260(0.986)$ & $7.458 \mathrm{E}-4 \pm 5.016 \mathrm{E}-5$ & $7.353 \mathrm{E}-4 \pm 4.071 \mathrm{E}-5$ & $0.479(0.610)$ \\
\hline & Hippocampus & $1.789 \mathrm{E}-1 \pm 1.808 \mathrm{E}-2$ & $1.718 \mathrm{E}-1 \pm 2.599 \mathrm{E}-2$ & $0.331(0.986)$ & $1.060 \mathrm{E}-3 \pm 9.955 \mathrm{E}-5$ & $1.137 \mathrm{E}-3 \pm 1.312 \mathrm{E}-4$ & $0.047(0.543)$ \\
\hline & Pallidus & $2.858 \mathrm{E}-1 \pm 7.461 \mathrm{E}-2$ & $2.834 \mathrm{E}-1 \pm 6.856 \mathrm{E}-2$ & $0.917(0.986)$ & $7.404 \mathrm{E}-4 \pm 7.546 \mathrm{E}-5$ & $7.186 \mathrm{E}-4 \pm 6.519 \mathrm{E}-5$ & $0.341(0.597)$ \\
\hline & Putamen & $3.796 \mathrm{E}-1 \pm 4.950 \mathrm{E}-2$ & $3.799 \mathrm{E}-1 \pm 4.609 \mathrm{E}-2$ & $0.986(0.986)$ & $7.042 \mathrm{E}-4 \pm 5.156 \mathrm{E}-5$ & $6.994 \mathrm{E}-4 \pm 3.654 \mathrm{E}-5$ & $0.740(0.740)$ \\
\hline & Thalaus & $3.394 \mathrm{E}-1 \pm 2.126 \mathrm{E}-2$ & $3.445 \mathrm{E}-1 \pm 2.005 \mathrm{E}-2$ & $0.449(0.986)$ & $7.756 \mathrm{E}-4 \pm 2.454 \mathrm{E}-5$ & $7.883 \mathrm{E}-4 \pm 4.118 \mathrm{E}-5$ & $0.253(0.548)$ \\
\hline \multirow[t]{7}{*}{ Right } & Accumbens & $2.200 \mathrm{E}-1 \pm 2.602 \mathrm{E}-2$ & $2.229 \mathrm{E}-1 \pm 2.133 \mathrm{E}-2$ & $0.708(0.986)$ & $7.428 \mathrm{E}-4 \pm 4.843 \mathrm{E}-5$ & $7.227 \mathrm{E}-4 \pm 6.328 \mathrm{E}-5$ & $0.274(0.548)$ \\
\hline & Amygdala & $1.921 \mathrm{E}-1 \pm 2.306 \mathrm{E}-2$ & $1.767 \mathrm{E}-1 \pm 2.588 \mathrm{E}-2$ & $0.058(0.812)$ & $8.398 \mathrm{E}-4 \pm 5.058 \mathrm{E}-5$ & $8.649 \mathrm{E}-4 \pm 6.616 \mathrm{E}-5$ & $0.190(0.543)$ \\
\hline & Caudate & $3.751 \mathrm{E}-1 \pm 4.904 \mathrm{E}-2$ & $3.835 \mathrm{E}-1 \pm 5.488 \mathrm{E}-2$ & $0.617(0.986)$ & $7.514 \mathrm{E}-4 \pm 6.283 \mathrm{E}-5$ & $7.697 \mathrm{E}-4 \pm 1.305 \mathrm{E}-4$ & $0.578(0.641)$ \\
\hline & Hippocampus & $1.782 \mathrm{E}-1 \pm 1.556 \mathrm{E}-2$ & $1.730 \mathrm{E}-1 \pm 2.433 \mathrm{E}-2$ & $0.441(0.986)$ & $1.053 \mathrm{E}-3 \pm 8.750 \mathrm{E}-5$ & $1.120 \mathrm{E}-3 \pm 1.510 \mathrm{E}-4$ & $0.102(0.543)$ \\
\hline & Pallidus & $2.460 \mathrm{E}-1 \pm 4.995 \mathrm{E}-2$ & $2.482 \mathrm{E}-1 \pm 3.444 \mathrm{E}-2$ & $0.875(0.986)$ & $7.251 \mathrm{E}-4 \pm 7.014 \mathrm{E}-5$ & $7.072 \mathrm{E}-4 \pm 7.573 \mathrm{E}-5$ & $0.450(0.610)$ \\
\hline & Putamen & $4.013 \mathrm{E}-1 \pm 5.577 \mathrm{E}-2$ & $3.955 \mathrm{E}-1 \pm 5.906 \mathrm{E}-2$ & $0.753(0.986)$ & $6.985 \mathrm{E}-4 \pm 5.885 \mathrm{E}-5$ & $6.874 \mathrm{E}-4 \pm 6.969 \mathrm{E}-5$ & $0.595(0.641)$ \\
\hline & Thalaus & $3.535 \mathrm{E}-1 \pm 2.544 \mathrm{E}-2$ & $3.527 \mathrm{E}-1 \pm 1.877 \mathrm{E}-2$ & $0.911(0.986)$ & $7.734 \mathrm{E}-4 \pm 1.685 \mathrm{E}-5$ & $7.811 \mathrm{E}-4 \pm 3.541 \mathrm{E}-5$ & $0.397(0.610)$ \\
\hline
\end{tabular}

Data given in mean \pm standard deviation (SD).

ADC is measured in millimeter squared per seconds $\left(\mathrm{mm}^{2} / \mathrm{s}\right)$.

Significant $\mathrm{p}$-value displayed in italics $(\mathrm{p} \leq 0.05)$.

Among the $p$-values showing significant differences, the values that passed the FDR correction $(\mathrm{p} \leq 0.2)$ are displayed in bold.

FA, fractional anisotropy; ADC, apparent diffusion coefficient. 
$\mathbf{A}$

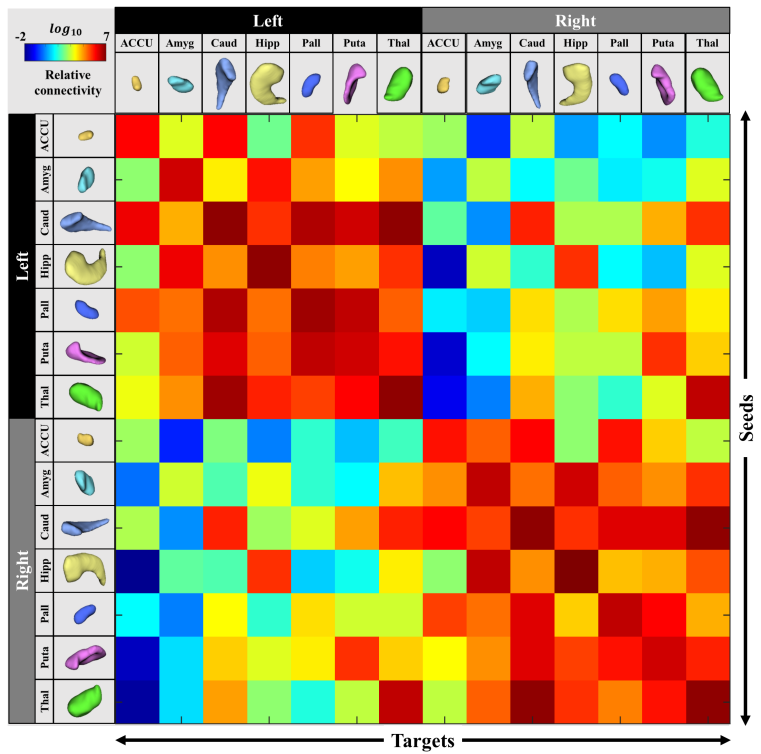

C

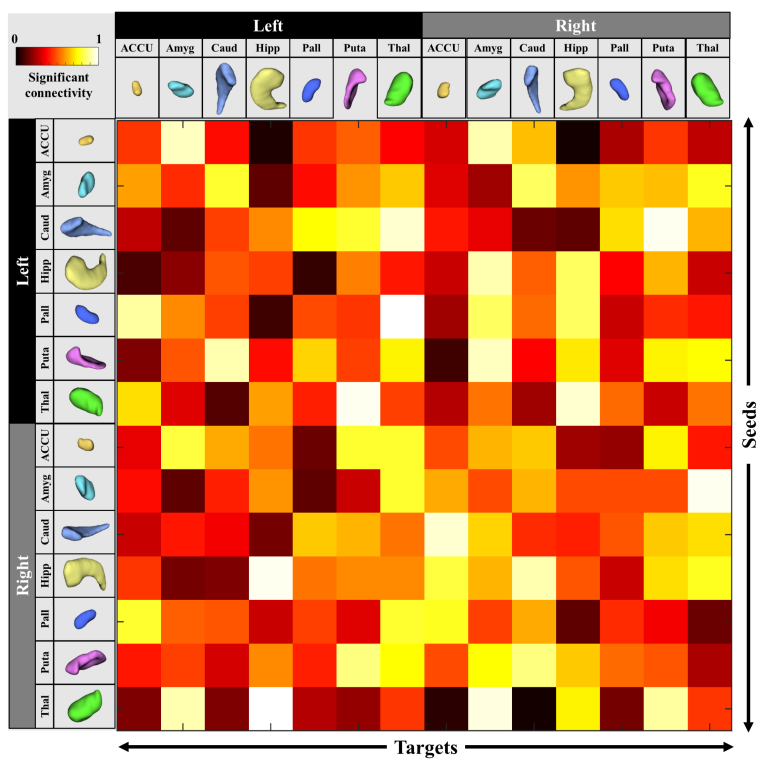

B

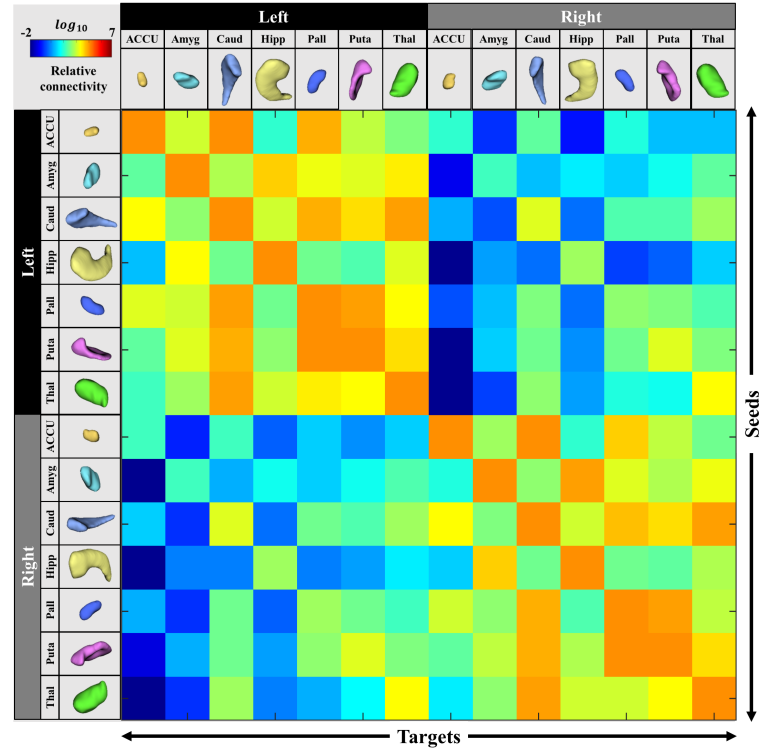

$\mathbf{D}$

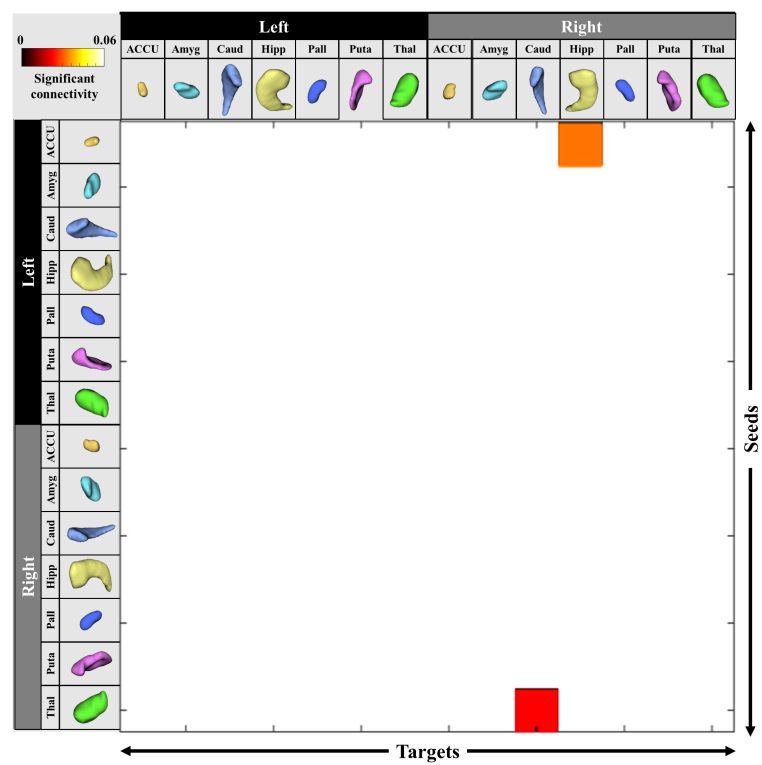

Fig. 5. Connectivity matrix map using DTI analysis results. Control group connectivity matrix map (A), SD group connectivity matrix map (B), Subcortical area connectivity matrix between two groups (C), connectivity matrix with significant difference (D). The link matrix was estimated between 14 anatomical areas on a logarithmic 10 scale color map. Tractography seed is shown above, target shown in the left column, along with rendered volumes of each structural area.

more, subcortical areas divided into left and right hemispheres creates a connectivity matrix from four different hemispheric combinations of connection strengths in one matrix, each of which consists of left-left, left-right, right-left, and right-right. The average connectivity values in each group are represented in percentages as shown in Supplementary Table 3.

In Fig. 5A, B, the connectivity of the right hemisphere is higher than that of the left hemisphere, and the Control group has a higher connection strength than the SD groups connection. The connectivities of all regions are symmetrical around the diagonal at the center of the matrix map, and the connectivity on the same hemisphere is higher than that of the opposite.

The connectivity of subcortical areas in the Control group and SD group were analyzed through T-test statistics, and presented as matrices in Fig. 5C, D. The connectivities that showed significant differences in the subcortical area were the left nucleus 
accumbens-left hippocampus (p: 0.042), left nucleus accumbensright hippocampus ( $\mathrm{p}$ : 0.027), and right thalamus-right caudate (p: 0.018). However, the significant difference of left nucleus accumbens-left hippocampus connectivity did not pass the FDR correction ( $p>0.2)$. Independent T-test result values of each subcortical structures between the Control group and SD group and the average connectivity values in each group are shown in Supplementary
Table 4.

Fiber paths showing statistically significant differences are plotted in Fig. 6. The connectivity of each group were averaged and compared. the SD group showed lower connectivity intensity in the left nucleus accumbens-right hippocampus (FDR p: 0.190) (Fig. 6A), and in the right thalamus-right caudate (FDR p: 0.129) (Fig. 6B).
$\mathbf{A}$

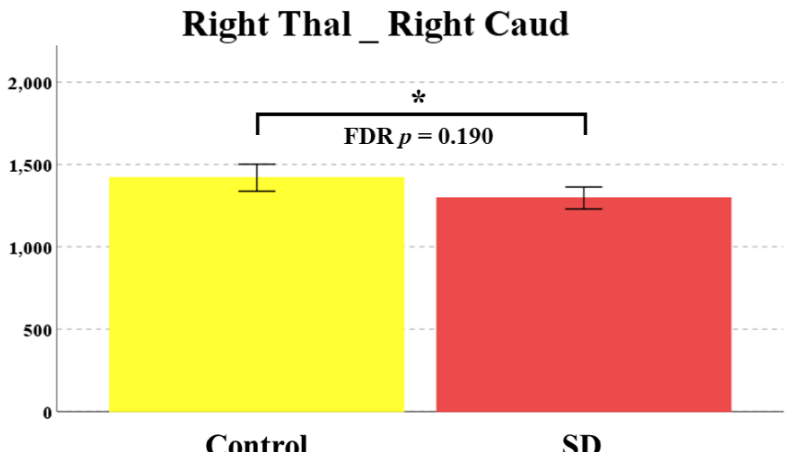

B

\section{Left Accu _ Right Hipp}

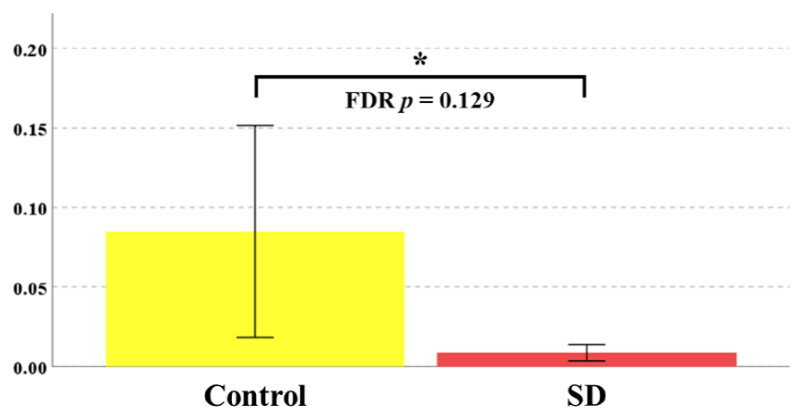

Fig. 6. Comparison graphs of segmented subcortical significant structure connection intensity between control and SN group. The right thalamus-right caudate (A) and left accumbens-right hippocampus (B). The p-values $\left(^{*}\right)$ that passed the FDR correction are displayed (p $\left.\leq 0.2\right)$. Yellow: control, Red: SD. L, Left; R, Right; Thal, Thalamus; Caud, Caudate; Accu, Nucleus Accumbens; Hipp, Hippocampus.

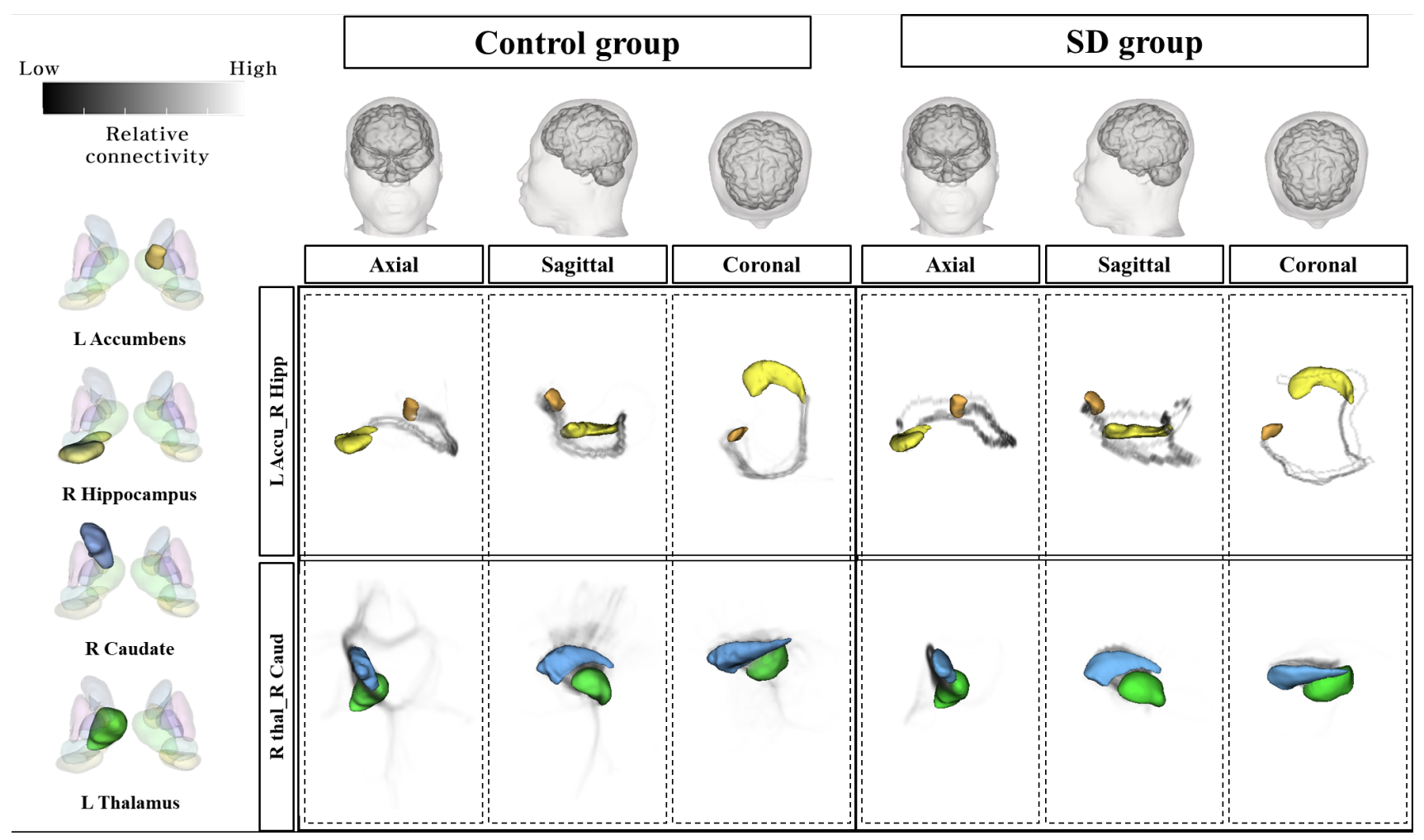

Fig. 7. The significant difference of connection between subcortical areas is 3D rendered. Pathway connection strength is expressed in accordance with a logarithmic 10 scale gray map. The rendered structure and connection strength were presented in Axial, Sagittal, and Coronal (Top), and the exact location of the structural area was rendered on the left. L, Left; R, Right; Accu, Nucleus Accumbens; Hipp, Hippocampus; Thal, Thalamus; Caud, Caudate. 
The connectivities between structures that show significant differences from the T-test statistical analysis are 3D rendered in Fig. 7. Left side of the figure shows two areas with statistically significant connectivity difference, with the brain directions of the Control group and the SD group displayed at the top of the figure. Interstructural connectivities, expressed in grayscale, shows weaker connection strength closer the fiber color is to black, and stronger connection strength closer the fiber color is to white. The track shape of the Control group and the SD group, which indicates the connectivity between each area, exhibits strong connections mostly in the same location, excluding minor twig-like protrusions. Control group with connectivity stronger than that of the SD group, are as follows: left nucleus accumbens-right hippocampus (Control group: 0.085, SD group: 0.009), and right thalamus-right caudate (Control group: 1420, SD group: 1295). The aforementioned results are consistent with the connectivity matrix shown in Fig. 5, the control group showing stronger connectivity strength than the disease group's connectivity.

\section{The relationship between the connection intensity of hippocampus and thalamus and neuropsychological examination}

In Table 6, 7 and Fig. 8, the intensity of the WM connectivity from the hippocampus and thalamus to the rest of the subcortical area was examined to see if the connectivity intensity correlates with scores of neuropsychological tests (e.g. Word list Recall, Word list Recognition, and Verbal fluency test).

The Control group showed no significant correlations with WM connectivity and the world list recall test scores while the SD group's left hippocampus-right hippocampus ( $r$ : -0.525 , p: 0.021$)$, right hippocampus-left hippocampus ( $r$ : -0.500, p: 0.029), and right hippocampus-left thalamus ( $r$ : -0.476 , p: 0.039) showed negative correlations with WM connectivity and test scores. When testing for correlation between WM connectivity and word list recognition test scores, negative correlation was found in the connection intensity of control group left hippocampus ( $r$ : -0.444 , p: 0.050), and positive correlation was found in SD group left hippocampusleft globus pallidus ( $r$ : 0.467, p: 0.044). When testing verbal fluency test scores for correlation with WM connectivity, negative correlation was found only in the connection intensity between the left hippocampus and the right hippocampus ( $r:-0.470$, p: 0.037) of the control group. However, the significant correlations that passed FDR correction $(\mathrm{p} \leq 0.2)$ were limited to negative correlations with word list recall test scores and connectivity intensities of left hippocampus-right hippocampus ( $r$ : -0.525 , FDR p: 0.148), right hippocampus-left hippocampus ( $r$ :-0.500, FDR p: 0.138) and right hippocampus-left thalamus ( $r$ : -0.476 , FDR p: 0.138 ) as shown in Table 6.

Table 6. Each group's correlation coefficients of connectivity intensity between hippocampus and all other subcortical regions with neuropsychological test scores

\begin{tabular}{|c|c|c|c|c|c|c|c|c|c|c|c|c|c|}
\hline & \multirow{3}{*}{ ROI } & \multicolumn{4}{|c|}{ Word list recall } & \multicolumn{4}{|c|}{ Word list recognition } & \multicolumn{4}{|c|}{ Verbal fluency test } \\
\hline & & \multicolumn{2}{|c|}{ Control group } & \multicolumn{2}{|c|}{ SD group } & \multicolumn{2}{|c|}{ Control group } & \multicolumn{2}{|c|}{ SD group } & \multicolumn{2}{|c|}{ Control group } & \multicolumn{2}{|c|}{ SD group } \\
\hline & & Left & Right & Left & Right & Left & Right & Left & Right & Left & Right & Left & Right \\
\hline \multirow[t]{7}{*}{ Left } & Accumbens & -.201 & -.139 & .133 & -.018 & -.330 & .164 & .047 & .023 & -.279 & .044 & -.123 & -.148 \\
\hline & Amygdala & -.090 & -.130 & .195 & -.331 & -.007 & .085 & .205 & .156 & .006 & -.222 & .158 & .287 \\
\hline & Caudate & -.114 & -.192 & -.012 & -.302 & .027 & .367 & .171 & -.084 & -.108 & -.356 & -.008 & -.053 \\
\hline & Hippocampus & -.324 & -.100 & -.019 & $-.500^{*}$ & $-.444^{*}$ & .095 & -.232 & .024 & -.347 & -.418 & .035 & .064 \\
\hline & Pallidus & .073 & -.098 & -.059 & .122 & -.143 & .119 & $.467^{\star}$ & -.206 & -.020 & .053 & .228 & -.239 \\
\hline & Putamen & -.252 & -.171 & -.198 & .035 & -.202 & .059 & -.049 & -.289 & .236 & .069 & .240 & -.072 \\
\hline & Thalamus & .056 & -.344 & .002 & $-.476^{\star}$ & .070 & -.024 & .178 & -.036 & -.093 & -.149 & -.125 & .338 \\
\hline \multirow[t]{7}{*}{ Right } & Accumbens & -.118 & .008 & -.159 & .011 & .183 & .129 & .287 & -.092 & .041 & .069 & .409 & .021 \\
\hline & Amygdala & .021 & -.055 & -.417 & -.019 & .193 & -.113 & .117 & -.039 & -.121 & -.110 & .016 & -.310 \\
\hline & Caudate & .035 & -.007 & -.288 & .001 & .274 & .381 & .056 & -.045 & .055 & -.264 & -.086 & .048 \\
\hline & Hippocampus & -.252 & -.319 & $-.525^{\star}$ & -.020 & .062 & -.430 & .098 & -.258 & $-.470^{*}$ & -.356 & .104 & .022 \\
\hline & Pallidus & -.044 & .297 & -.265 & .370 & .135 & -.029 & .314 & .177 & .051 & .067 & .180 & -.073 \\
\hline & Putamen & -.160 & -.390 & -.160 & -.118 & -.043 & .182 & -.103 & -.121 & .140 & -.375 & -.035 & .019 \\
\hline & Thalamus & .125 & .039 & -.188 & -.203 & -.050 & -.061 & -.075 & .188 & -.030 & .244 & -.037 & .266 \\
\hline
\end{tabular}

For the connectivity between the hippocampus and other subcortical areas, the hippocampus is the seed region, and all the other subcortical areas is the target.

In the left column presenting the target area, the connectivity of the hippocampus, in the left and right hemispheres, are shown under each neuropsychological test.

${ }^{\star}$ Significance of correlation at 0.05 level (2-tailed).

Among the $\mathrm{p}$-values showing significant differences, the values that passed the FDR correction $(\mathrm{p} \leq 0.2)$ are displayed in bold. 
Table 7. The Control and SD group's correlation coefficients of connectivity intensity from the thalamus to all other subcortical regions with neuropsychological test scores

\begin{tabular}{|c|c|c|c|c|c|c|c|c|c|c|c|c|c|}
\hline & \multirow{3}{*}{ ROI } & \multicolumn{4}{|c|}{ Word list recall } & \multicolumn{4}{|c|}{ Word list recognition } & \multicolumn{4}{|c|}{ Verbal fluency test } \\
\hline & & \multicolumn{2}{|c|}{ Control group } & \multicolumn{2}{|c|}{ SD group } & \multicolumn{2}{|c|}{ Control group } & \multicolumn{2}{|c|}{ SD group } & \multicolumn{2}{|c|}{ Control group } & \multicolumn{2}{|c|}{ SD group } \\
\hline & & Left & Right & Left & Right & Left & Right & Left & Right & Left & Right & Left & Right \\
\hline \multirow[t]{7}{*}{ Left } & Accumbens & -.162 & -.166 & .311 & -.071 & .153 & -.329 & .382 & -.033 & -.311 & -.265 & -.067 & -.247 \\
\hline & Amygdala & .081 & .279 & -.002 & -.445 & -.155 & .345 & .113 & .128 & .407 & .221 & .167 & .145 \\
\hline & Caudate & -.226 & .020 & -.137 & $-.541^{\star}$ & .061 & .198 & -.005 & -.056 & -.305 & -.020 & .126 & -.153 \\
\hline & Hippocampus & .010 & .049 & -.124 & -.289 & -.207 & .035 & .104 & .134 & -.088 & -.008 & .119 & .249 \\
\hline & Pallidus & .104 & .232 & $-.465^{\star}$ & -.404 & .032 & -.127 & .334 & .193 & .060 & .037 & .050 & .075 \\
\hline & Putamen & -.299 & -.066 & -.164 & -.401 & .080 & .117 & .045 & .024 & -.144 & .009 & .239 & .041 \\
\hline & Thalamus & -.332 & -.368 & -.038 & $-.494^{*}$ & -.442 & -.105 & -.246 & -.089 & -.337 & -.238 & .025 & .052 \\
\hline \multirow[t]{7}{*}{ Right } & Accumbens & -.105 & .130 & -.197 & $.528^{\star}$ & .202 & -.315 & .294 & .304 & .033 & -.041 & .113 & .020 \\
\hline & Amygdala & .308 & .283 & -.211 & .019 & .301 & .335 & .027 & .014 & .178 & .401 & .258 & -.002 \\
\hline & Caudate & .062 & -.291 & $-.524^{\star}$ & -.003 & .197 & -.373 & .046 & -.166 & -.053 & -.219 & -.109 & -.067 \\
\hline & Hippocampus & .048 & .154 & -.006 & -.139 & .043 & .092 & .007 & .254 & -.103 & .054 & -.236 & .278 \\
\hline & Pallidus & .176 & .276 & $-.515^{\star}$ & .312 & .159 & -.271 & .190 & .258 & .124 & .015 & .036 & .044 \\
\hline & Putamen & .086 & -.028 & -.442 & -.001 & .067 & .269 & .123 & .001 & .125 & -.092 & .076 & .120 \\
\hline & Thalamus & -.325 & -.323 & $-.499^{*}$ & -.032 & -.079 & $-.461^{\star}$ & -.087 & -.231 & -.226 & -.353 & .058 & .026 \\
\hline
\end{tabular}

For the instance of the connectivity between the thalamus and other subcortical areas, the thalamus becomes the seed region, and all the other subcortical areas as the target. The left column presenting the target area, the connectivity of the thalamus, which is the seed area of the Control and SD group, in the left and right hemispheres, are shown under each neuropsychological test.

${ }^{*}$ Significance of correlation at 0.05 level (2-tailed).

Among the $p$-values showing significant differences, the values that passed the FDR correction $(p \leq 0.2)$ are displayed in bold.

The Control groups subcortical connectivity intensity from the thalamus had no significant correlations with the word list recall test scores (FDR p $>0.2$ ). However, the SD groups connectivity intensity in the left thalamus-left globus pallidus ( $r:-0.465$, p: 0.045), left thalamus-right caudate ( $r$ : -0.524, p: 0.021), left thalamus-right globus pallidus ( $r:-0.515, \mathrm{p}: 0.024)$, right thalamus-left pallidum ( $r$ : -0.442, p: 0.058), left thalamus-right thalamus ( $r:-0.499$, p: 0.030 ), right thalamus-left caudate ( $r:-0.541$, p: 0.017$)$ and right thalamusright thalamus ( $r:-0.494$, p: 0.031) showed negative correlation with word list recall test scores and positive correlation with the right thalamus-right accumbens ( $r: 0.528, \mathrm{p}: 0.020)$ and test scores. For word list recognition tests scores, the only negative correlation found in the Control group was in the right thalamus $(r:-0.461$, p: 0.041), while no significant correlations with the Verbal fluency test were found. Negative correlations with word list test scores and connectivity intensities of thalamus, left thalamus-right caudate $(r$ : -0.524, FDR p: 0.069), left thalamus-right globus pallidus ( $r:-0.515$, FDR p: 0.069), all survived FDR correction. Positive correlations with word list test scores and connectivity intensities of left thalamus-right thalamus ( $r:-0.499$, FDR p: 0.069), right thalamus-left caudate ( $r:-0.541$, FDR p: 0.110$)$ and right thalamus-right thalamus ( $r$ :-0.494, FDR p: 0.110) and right thalamus-right accumbens $(r: 0.528$, FDR $p: 0.141)$, passed the FDR correction (FDR $\mathrm{p} \leq 0.2)$ as shown in Table 7.

Significant structural connectivity that passed the FDR correc- tion is presented graphically in Fig. 8.

\section{DISCUSSION}

We conducted neuropsychological tests on seniors, classified them into Control and SD groups and obtained brain image data using 3Tesla MRI. Using the acquired image data, differences in structural aspects were observed by dividing subcortical areas into left and right hemispheres, and the connectivity of each structural area was investigated using probabilistic tractography. The results of this study were compared to the results of previous research on depression-related brain structural change. Previous studies have shown that people with subclinical asymptomatic depression have an increased risk of developing depression, and a biomarker test for early detection of depression has shown to help detect early symptoms $[7,8]$. The consensuses upon depression-related brain structures in previous studies are that the subcortical areas are mostly smaller than healthy brain structures and shows structural asymmetry in the left and right hemispheres of the brain [33]. It is also known that loss of integrity on WM fibers occurs in brains of subjects with depression, which correlates with low connectivity in subcortical areas [61].

By using FIRST from FSL, the left and right hemisphere subcortical structures were segmented. The seven segmented areas (e.g., Nucleus Accumbens, Amygdala, Caudate, Hippocampus, Globus 


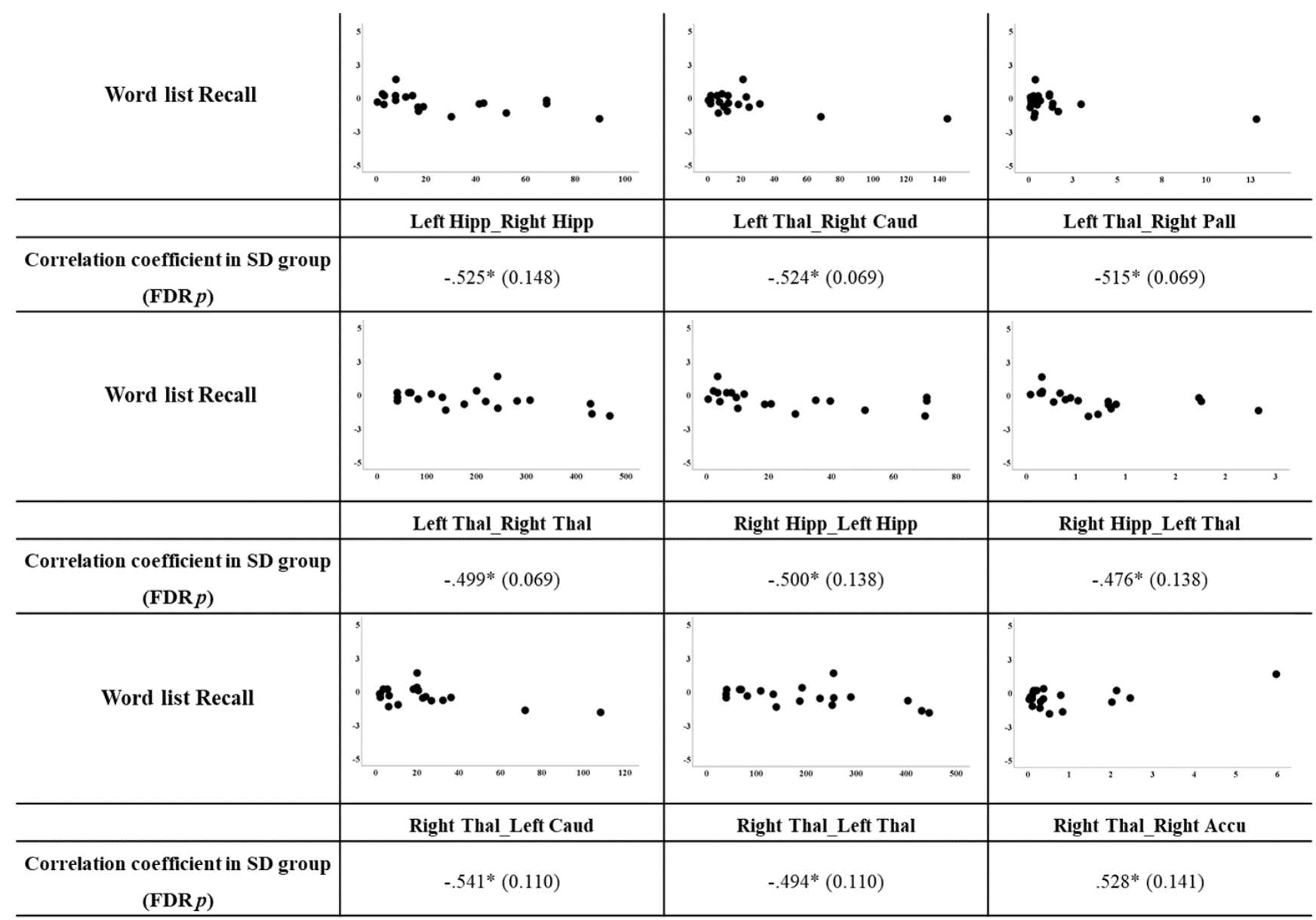

Fig. 8. A scatterplot graph of the correlation between the connection pathways and neuropsychological test scores showing significant differences. The horizontal axis of the graph is the strength of the connection between structures showing significant differences, and the vertical axis is the neuropsychological test score of $\mathrm{z}$-score. Only the significant $\mathrm{p}$-values that passed the FDR correction $(\mathrm{p} \leq 0.2)$ are displayed. Accu, Nucleus Accumbens; Caud, Caudate; Hipp, Hippocampus; Pall, Pallidus; Thal, Thalamus.

pallidus, Putamen, and Thalamus) were overlaid in MPRAGE to evaluate if the structures were well fitted in the correct position as shown in previous studies. In quantitative analysis, most structures were smaller in the SD group as shown in previous studies, and the quantified values such as FA and ADC were mostly shown to be smaller in the SD group. Furthermore, the quantified values were larger in the left hemisphere than the right hemisphere in both the Control group and the SD group. However, no quantified values showed statistically significant differences (FDR p >0.2). The hemispherical asymmetry appeared in both control and depression groups. Asymmetries from the controls and depressions were similar to each other, and the left hemisphere asymmetry prevailed in cortical areas. These findings were consistent with the previous studies [62-65]. However, when comparing the left and right hemisphere asymmetry between groups, no statistically significant difference was found (FDR p >0.2). Hemispheric asymmetry patterns are critical in identifying certain structural anomalies associated with mental and nervous system diseases such as Attention Deficit/Hyperactivity Disorder (ADHD), schizophrenia and Alzheimer's disease, etc. [66, 67]. Since hemispherical asymmetry patterns are identifiable for specific structural anomalies associated with mental and neurological disorders, further studies with larger sample sizes are needed in the future.

Through probabilistic tractography analysis, the connectivity between the detailed areas of each subcortical region was investigated in the form of a matrix for visualizing strong and weak interhemispheric connectivity. Consistent with previous studies, the connectivity between structures at a closer distance was stronger than that of in the far [68]. Comparisons between the two groups showed that the Control group had higher connection intensity than the SD group and that statistically significant differences in connection pathways were found in left nucleus accumbens-right hippocampus and right thalamus-right caudate. A decrease in hippocampus-related connection strength in SD group has shown 
that it can affect emotional and cognitive disorders such as anxiety and depression and quantifying the network measurements of such hippocampal networks can help assess cognitive impairment across clinical conditions $[64,69]$. Moreover, results showed that there was a significant correlation between each structure's connectivity and neuropsychological test scores. The connectivity of the hippocampus and thalamus, structures that greatly influence depression, showed more correlations in the SD group than in the Control group [70]. Out of all the neuropsychological tests, the Wordlist Recall test showed the most prominent correlations.

Nucleus accumbens, a structure involved in the reward system and related to depressive symptoms such as anhedonia, showed structural and functional alteration in depression patients [71]. The mechanism by which nucleus accumbens affects depressive symptoms can be inferred from studies using mouse models to study the synaptic connection between accumbens and hippocampus. Specifically, the neurotransmission of synapses spanning from hippocampus to accumbens is shown to decrease when undergoing chronic social defeat stress [72]. Additionally, improvement of synaptic plasticity and neurotransmitter modulation between hippocampus and nucleus accumbens were found in subjects adapting escapist behavior to deal with hopeless situations. Thus, the weakened WM connectivity between left accumbens and right hippocampus in SD subjects identified in our study may represent synaptic dysfunction reflected in microstructural alterations of subcortical structures, frequently observed in subjects with depressive spectrum disorder, particularly before volumetric changes of subcortical structures occur.

In the SD group, the WM connectivity of thalamus and caudate were found to be weaker than those of control group. Caudate forms a reward network with the frontal cortex and nucleus accumbens. According to previous studies, caudate volume did not show a significant difference between healthy controls and patients with mild to moderate depression as well as late life depression, which is consistent with the results of this study [73]. In patients with depression, functional alteration is mainly observed over structural alteration in the caudate as described in studies showing reduced functional connectivity of anterior cingulate cortex and caudate in depression group, possibly affecting motivation level of subjects with depression [74, 75]. The pattern of significantly weaker thalamus to caudate connectivity in SD group when compared with healthy controls in this study supports the evidence that microstructural alteration of caudate may be related to motivation and anhedonia symptoms that occur in depression patients.

Results of this study showed a relationship between subcortical structural WM connectivity and verbal recall and recognition.
The level of verbal recall in the SD group was lower than that of the control group, followed by a negative correlation with interhemispheric hippocampal connectivity. The structural and functional characteristics of the hippocampus are particularly related to memory performance $[76,77]$, with hippocampal asymmetry predicting accurate treatment response to memory dysfunction of depression [78]. Hippocampus, unlike other subcortical structures, establishes interhemispheric connection through the fornix [79]. According to rsFMRI research, hippocampus shows functional asynchrony in dementia patients with Alzheimer's disease [80]. Studies have shown that interhemispheric functional connectivity related to memory performance is reduced in dementia patients $[81,82]$, and may be improved through exercise [83]. Similar to the results in our study, interhemispheric hippocampal connectivity and verbal memory showed a negative correlation in those who suffered traumatic axonal injury [84]. In the study, the mean diffusivity of hippocampal interhemispheric microstructural connections was also inversely correlated with verbal recognition [85]. The results of this study may be evidence of a negative correlation between interhemispheric hippocampal microstructural connectivity and verbal memory performance in SD.

Changes in subcortical levels of dopamine, a neurotransmitter that plays specific roles in controlling various aspects of cognitive abilities have shown to contribute to neurological disorders [86]. Hence, cognitive defects from changes in levels of dopamine are likely to be located in subcortical areas characterized by dense connectivity. The current study shows that, similar to results of previous depression studies, the connection strength between subcortical areas is smaller in the SD group than that of the Control group, and the differences can be visualized in diffusion pathways of each structure $[33,65]$. The specific role of the subcortical areas investigated in this study is related to neuropsychiatric disorders, similar to previous studies reporting effects of microstructure damage in the brain of senior depression patients [87-89]. Such data support the notion that the effects of structural changes on the brain generally leads to changes in the dopaminergic pathways, which can cause emotion and cognition disorders (e.g., depression, decreased motivation, and insensitivity) [90-92].

Our research investigated the changes in brain structure related to $\mathrm{SD}$ in the aged group, and our results show that the network defects in the subcortical area can help explain the cognitive disorders frequently occurring in seniors, most notably depression. However, the sample size is too small to make a definitive conclusion, and extension from sectional analysis to a longitudinal examination using a larger sample size is needed. There have been previous studies that have documented significant affects that age has on connectivity [93-95], but our results showed that neither 
age nor sex showed any significant influence on our analysis. However, it is possible that the imbalance of measured covariates between subjects of control and SD groups may have influenced our results $[96,97]$. Additionally, all participants in the study were recruited through one selected institution, which may introduce potential bias as the recruited SD subjects were localized to a small location and may not represent the results of a general population of SD [98]. Also, factors that could have influenced the results such as the duration of the disease from the diagnosed date, the treatment status, and the recurrence of the disease during treatment were excluded. Another limitation of our study is that the history of subjects' internal diseases (e.g. cardiovascular disease, diabetes and metabolic disorders) that could influence our results were not considered for our study. In addition, the FDR correction used in this study to solve for multiple comparisons after statistically analyzing the differences between groups (e.g. comparing each structural volume and connectivities (FA and ADC)) may have introduced false positives due to being less conservative than the Bonferroni method. Finally, it was investigated by psychiatrists to evaluate with proven tools such as MMSE and SGDS and define $\mathrm{SD}$, but this is likely to be limited to the diagnosis of major SD disorders. Future studies should consider more specific interviews to establish formal SD related changes in the brain. Additionally, probabilistic tractography analysis has limitations on deducing the direction of the connection, therefore, cannot reflect the direction of projection in the region of interest, making distinguishing the inhibitory and excitability of the acquired fibers difficult.

The results of this study confirm that there is a difference in the strength of the network in subcortical areas between the control group and the depression group, and the reduced volume in the region of interest could reflect cognitive degradation in the senior depression group. These results will be useful in distinguishing image markers of cognitive degradation in old depression patients and may serve as reference databases for further research with depression patients.

In conclusion, we present the results of MRI brain analysis study targeting SD in the elderly. The acquired brain MRI data was used to compare subcortical volume and connectivity in Control group and SD group using FSL. Results of our study were similar to previous depression studies with the volume of the subcortical structural area of the SD group being mostly smaller than that of the Control group, and structural asymmetry of left and right hemisphere brain structures shown in both control and SD groups. However, no statistically significant difference was found between the volumetric analysis and the asymmetry test results. The connection intensity between subcortical structural regions was lower in the SD group than in the Control group. These results support the notion that the influence of structural changes in subcortical structural domains related to neuropsychiatric disorders can induce emotional and cognitive impairment. The description of the connectivity between the subcortical structural regions described in this study will be helpful in early symptom detection and disease evaluation in SD as well as putative biomarker tests for early detection of depression.

\section{REFERENCES}

1. Alexopoulos GS (2019) Mechanisms and treatment of latelife depression. Transl Psychiatry 9:188.

2. Zhao K, Liu H, Yan R, Hua L, Chen Y, Shi J, Lu Q, Yao Z (2017) Cortical thickness and subcortical structure volume abnormalities in patients with major depression with and without anxious symptoms. Brain Behav 7:e00754.

3. Goldberg DP (2014) Anxious forms of depression. Depress Anxiety 31:344-351.

4. Manning KJ, Steffens DC (2018) State of the science of neural systems in late-life depression: impact on clinical presentation and treatment outcome. J Am Geriatr Soc 66(Suppl 1):S17S23.

5. Murray CJ, Vos T, Lozano R, Naghavi M, Flaxman AD, Michaud C, Ezzati M, Shibuya K, Salomon JA, Abdalla S, Aboyans V, Abraham J, Ackerman I, Aggarwal R, Ahn SY, Ali MK, Alvarado M, Anderson HR, Anderson LM, Andrews KG, Atkinson C, Baddour LM, Bahalim AN, Barker-Collo S, Barrero LH, Bartels DH, Basáñez MG, Baxter A, Bell ML, Benjamin EJ, Bennett D, BernabéE, Bhalla K, Bhandari B, Bikbov B, Bin Abdulhak A, Birbeck G, Black JA, Blencowe H, Blore JD, Blyth F, Bolliger I, Bonaventure A, Boufous S, Bourne R, Boussinesq M, Braithwaite T, Brayne C, Bridgett L, Brooker S, Brooks P, Brugha TS, Bryan-Hancock C, Bucello C, Buchbinder R, Buckle G, Budke CM, Burch M, Burney P, Burstein R, Calabria B, Campbell B, Canter CE, Carabin H, Carapetis J, Carmona L, Cella C, Charlson F, Chen H, Cheng AT, Chou D, Chugh SS, Coffeng LE, Colan SD, Colquhoun S, Colson KE, Condon J, Connor MD, Cooper LT, Corriere M, Cortinovis M, de Vaccaro KC, Couser W, Cowie BC, Criqui MH, Cross M, Dabhadkar KC, Dahiya M, Dahodwala N, Damsere-Derry J, Danaei G, Davis A, De Leo D, Degenhardt L, Dellavalle R, Delossantos A, Denenberg J, Derrett S, Des Jarlais DC, Dharmaratne SD, Dherani M, Diaz-Torne C, Dolk H, Dorsey ER, Driscoll T, Duber H, Ebel B, Edmond K, Elbaz A, Ali SE, Erskine H, Erwin PJ, Espindola P, Ewoigbokhan SE, Farzadfar F, Feigin V, Felson DT, Ferrari A, Ferri CP, Fèvre EM, Finucane MM, Flaxman S, Flood L, Foreman K, Forouzanfar 
MH, Fowkes FG, Fransen M, Freeman MK, Gabbe BJ, Gabriel SE, Gakidou E, Ganatra HA, Garcia B, Gaspari F, Gillum RF, Gmel G, Gonzalez-Medina D, Gosselin R, Grainger R, Grant B, Groeger J, Guillemin F, Gunnell D, Gupta R, Haagsma J, Hagan H, Halasa YA, Hall W, Haring D, Haro JM, Harrison JE, Havmoeller R, Hay RJ, Higashi H, Hill C, Hoen B, Hoffman H, Hotez PJ, Hoy D, Huang JJ, Ibeanusi SE, Jacobsen KH, James SL, Jarvis D, Jasrasaria R, Jayaraman S, Johns N, Jonas JB, Karthikeyan G, Kassebaum N, Kawakami N, Keren A, Khoo JP, King CH, Knowlton LM, Kobusingye O, Koranteng A, Krishnamurthi R, Laden F, Lalloo R, Laslett LL, Lathlean T, Leasher JL, Lee YY, Leigh J, Levinson D, Lim SS, Limb E, Lin JK, Lipnick M, Lipshultz SE, Liu W, Loane M, Ohno SL, Lyons R, Mabweijano J, MacIntyre MF, Malekzadeh R, Mallinger L, Manivannan S, Marcenes W, March L, Margolis DJ, Marks GB, Marks R, Matsumori A, Matzopoulos R, Mayosi BM, McAnulty JH, McDermott MM, McGill N, McGrath J, Medina-Mora ME, Meltzer M, Mensah GA, Merriman TR, Meyer AC, Miglioli V, Miller M, Miller TR, Mitchell PB, Mock C, Mocumbi AO, Moffitt TE, Mokdad AA, Monasta L, Montico M, Moradi-Lakeh M, Moran A, Morawska L, Mori R, Murdoch ME, Mwaniki MK, Naidoo K, Nair MN, Naldi L, Narayan KM, Nelson PK, Nelson RG, Nevitt MC, Newton CR, Nolte S, Norman P, Norman R, O'Donnell M, O'Hanlon S, Olives C, Omer SB, Ortblad K, Osborne R, Ozgediz D, Page A, Pahari B, Pandian JD, Rivero AP, Patten SB, Pearce N, Padilla RP, Perez-Ruiz F, Perico N, Pesudovs K, Phillips D, Phillips MR, Pierce K, Pion S, Polanczyk GV, Polinder S, Pope CA 3rd, Popova S, Porrini E, Pourmalek F, Prince M, Pullan RL, Ramaiah KD, Ranganathan D, Razavi H, Regan M, Rehm JT, Rein DB, Remuzzi G, Richardson K, Rivara FP, Roberts T, Robinson C, De Leòn FR, Ronfani L, Room R, Rosenfeld LC, Rushton L, Sacco RL, Saha S, Sampson U, Sanchez-Riera L, Sanman E, Schwebel DC, Scott JG, Segui-Gomez M, Shahraz S, Shepard DS, Shin H, Shivakoti R, Singh D, Singh GM, Singh JA, Singleton J, Sleet DA, Sliwa K, Smith E, Smith JL, Stapelberg NJ, Steer A, Steiner T, Stolk WA, Stovner LJ, Sudfeld C, Syed S, Tamburlini G, Tavakkoli M, Taylor HR, Taylor JA, Taylor WJ, Thomas B, Thomson WM, Thurston GD, Tleyjeh IM, Tonelli M, Towbin JA, Truelsen T, Tsilimbaris MK, Ubeda C, Undurraga EA, van der Werf MJ, van Os J, Vavilala MS, Venketasubramanian N, Wang M, Wang W, Watt K, Weatherall DJ, Weinstock MA, Weintraub R, Weisskopf MG, Weissman MM, White RA, Whiteford H, Wiebe N, Wiersma ST, Wilkinson JD, Williams HC, Williams SR, Witt E, Wolfe F, Woolf AD, Wulf S, Yeh PH, Zaidi AK, Zheng ZJ, Zonies D, Lopez AD, AlMazroa MA, Memish ZA. Disability-adjusted life years (DALYs) for
291 diseases and injuries in 21 regions, 1990-2010: a systematic analysis for the Global Burden of Disease study 2010. Lancet 380:2197-2223.

6. Chang KJ, Hong CH, Kim SH, Lee KS, Roh HW, Kang DR, Choi SH, Kim SY, Na DL, Seo SW, Kim DK, Lee Y, Chung YK, Lim KY, Noh JS, Son SJ (2016) MRI-defined versus clinicallydefined vascular depression; comparison of prediction of functional disability in the elderly. Arch Gerontol Geriatr 66:7-12.

7. Cuijpers P, Smit F (2008) [Subclinical depression: a clinically relevant condition?] Tijdschr Psychiatr 50:519-528. Dutch.

8. Besteher B, Gaser C, Langbein K, Dietzek M, Sauer H, Nenadić I (2017) Effects of subclinical depression, anxiety and somatization on brain structure in healthy subjects. J Affect Disord 215:111-117.

9. Mills KL, Tamnes CK (2014) Methods and considerations for longitudinal structural brain imaging analysis across development. Dev Cogn Neurosci 9:172-190.

10. Lemaitre H, Goldman AL, Sambataro F, Verchinski BA, Meyer-Lindenberg A, Weinberger DR, Mattay VS (2012) Normal age-related brain morphometric changes: nonuniformity across cortical thickness, surface area and gray matter volume? Neurobiol Aging 33:617.e1-617.e9.

11. Vijayakumar N, Mills KL, Alexander-Bloch A, Tamnes CK, Whittle S (2018) Structural brain development: a review of methodological approaches and best practices. Dev Cogn Neurosci 33:129-148.

12. Armstrong NM, An Y, Beason-Held L, Doshi J, Erus G, Ferrucci L, Davatzikos C, Resnick SM (2019) Sex differences in brain aging and predictors of neurodegeneration in cognitively healthy older adults. Neurobiol Aging 81:146-156.

13. Taylor WD, Hsu E, Krishnan KR, MacFall JR (2004) Diffusion tensor imaging: background, potential, and utility in psychiatric research. Biol Psychiatry 55:201-207.

14. Zhu X, Wang X, Xiao J, Zhong M, Liao J, Yao S (2011) Altered white matter integrity in first-episode, treatment-naive young adults with major depressive disorder: a tract-based spatial statistics study. Brain Res 1369:223-229.

15. Abhinav K, Yeh FC, Pathak S, Suski V, Lacomis D, Friedlander RM, Fernandez-Miranda JC (2014) Advanced diffusion MRI fiber tracking in neurosurgical and neurodegenerative disorders and neuroanatomical studies: a review. Biochim Biophys Acta 1842:2286-2297.

16. Tae WS, Ham BJ, Pyun SB, Kang SH, Kim BJ (2018) Current clinical applications of diffusion-tensor imaging in neurological disorders. J Clin Neurol 14:129-140.

17. Li M, Meng Y, Wang M, Yang S, Wu H, Zhao B, Wang G (2017) 
Cerebral gray matter volume reduction in subcortical vascular mild cognitive impairment patients and subcortical vascular dementia patients, and its relation with cognitive deficits. Brain Behav 7:e00745.

18. Jenkins LM, Chiang JJ, Vause K, Hoffer L, Alpert K, Parrish TB, Miller GE, Wang L (2020) Outward subcortical curvature associated with sub-clinical depression symptoms in adolescents. Neuroimage Clin 25:102187.

19. Kempton MJ, Salvador Z, Munafò MR, Geddes JR, Simmons A, Frangou S, Williams SC (2011) Structural neuroimaging studies in major depressive disorder. Meta-analysis and comparison with bipolar disorder. Arch Gen Psychiatry 68:675690.

20. Nugent AC, Davis RM, Zarate CA Jr, Drevets WC (2013) Reduced thalamic volumes in major depressive disorder. Psychiatry Res 213:179-185.

21. Tannous J, Amaral-Silva H, Cao B, Wu MJ, Zunta-Soares GB, Kazimi I, Zeni C, Mwangi B, Soares JC (2018) Hippocampal subfield volumes in children and adolescents with mood disorders. J Psychiatr Res 101:57-62.

22. Lyu H, Wang J, Xu J, Zheng H, Yang X, Lin S, Chen J, Zhou L, Hu Y, Guo Z (2019) Structural and functional disruptions in subcortical vascular mild cognitive impairment with and without depressive symptoms. Front Aging Neurosci 11:241.

23. Tannous J, Godlewska BR, Tirumalaraju V, Soares JC, Cowen PJ, Selvaraj S (2020) Stress, inflammation and hippocampal subfields in depression: a 7 Tesla MRI Study. Transl Psychiatry 10:78.

24. Zhang W, Zhou Y, Li Q, Xu J, Yan S, Cai J, Jiaerken Y, Lou M (2019) Brain iron deposits in thalamus is an independent factor for depressive symptoms based on quantitative susceptibility mapping in an older adults community population. Front Psychiatry 10:734.

25. Han KM, Choi S, Jung J, Na KS, Yoon HK, Lee MS, Ham BJ (2014) Cortical thickness, cortical and subcortical volume, and white matter integrity in patients with their first episode of major depression. J Affect Disord 155:42-48.

26. Travis SG, Coupland NJ, Hegadoren K, Silverstone PH, Huang Y, Carter R, Fujiwara E, Seres P, Malykhin NV (2016) Effects of cortisol on hippocampal subfields volumes and memory performance in healthy control subjects and patients with major depressive disorder. J Affect Disord 201:34-41.

27. Reynolds S, Carrey N, Jaworska N, Langevin LM, Yang XR, Macmaster FP (2014) Cortical thickness in youth with major depressive disorder. BMC Psychiatry 14:83.

28. Davidson RJ, Irwin W (1999) The functional neuroanatomy of emotion and affective style. Trends Cogn Sci 3:11-21.
29. Liu W, Mao Y, Wei D, Yang J, Du X, Xie P, Qiu J (2016) Structural asymmetry of dorsolateral prefrontal cortex correlates with depressive symptoms: evidence from healthy individuals and patients with major depressive disorder. Neurosci Bull 32:217-226.

30. Zuo Z, Ran S, Wang Y, Li C, Han Q, Tang Q, Qu W, Li H (2019) Asymmetry in cortical thickness and subcortical volume in treatment-naïve major depressive disorder. Neuroimage Clin 21:101614.

31. Briggs CA, Chakroborty S, Stutzmann GE (2017) Emerging pathways driving early synaptic pathology in Alzheimer's disease. Biochem Biophys Res Commun 483:988-997.

32. Cantone M, Bramanti A, Lanza G, Pennisi M, Bramanti P, Pennisi G, Bella R (2017) Cortical plasticity in depression. ASN Neuro 9:1759091417711512.

33. Li X, Steffens DC, Potter GG, Guo H, Song S, Wang L (2017) Decreased between-hemisphere connectivity strength and network efficiency in geriatric depression. Hum Brain Mapp 38:53-67.

34. Song YJ, Korgaonkar MS, Armstrong LV, Eagles S, Williams LM, Grieve SM (2014) Tractography of the brainstem in major depressive disorder using diffusion tensor imaging. PLoS One 9:e84825.

35. Korgaonkar MS, Cooper NJ, Williams LM, Grieve SM (2012) Mapping inter-regional connectivity of the entire cortex to characterize major depressive disorder: a whole-brain diffusion tensor imaging tractography study. Neuroreport 23:566571.

36. Niida A, Niida R, Kuniyoshi K, Motomura M, Uechi A (2013) Usefulness of visual evaluation of the anterior thalamic radiation by diffusion tensor tractography for differentiating between Alzheimer's disease and elderly major depressive disorder patients. Int J Gen Med 6:189-200.

37. Shooshtari MH, Davari-Ashtiani R, Shahrivar Z, Shabani A, Semnani Y, Kaviani H, Amini H, Mohammadi MR, Assadi SM, Sharifi V, Seddigh A, Jalali M. Structured clinical interview for DSM-IV (SCID Persian translation and cultural adaptation). Iran J Psychiatry 2:46-48.

38. Blow FC, Gillespie BW, Barry KL, Mudd SA, Hill EM (1998) Brief screening for alcohol problems in elderly populations using the Short Michigan Alcoholism Screening Test - Geriatric version (SMAST-G). Alcoholism: Clinical and Experimental Research 22:20-25.

39. Park JH, Park YN, Ko HJ (1991) Modification of the minimental state examination for use with the elderly in a nonwestern society. Part II: cutoff points and their diagnostic validities. Int J Geriatr Psychiatry 6(12):875-882. 
40. Bae JN, Cho MJ (2004) Development of the Korean version of the Geriatric Depression Scale and its short form among elderly psychiatric patients. J Psychosom Res 57:297-305.

41. Lee SC, Kim WH, Chang SM, Kim BS, Lee DW, Bae JN, Cho MJ (2013) The use of the Korean version of short form Geriatric Depression Scale (SGDS-K) in the community dwelling elderly in Korea. J Korean Geriatr Psychiatry 17:37-43.

42. Lee JH, Lee KU, Lee DY, Kim KW, Jhoo JH, Kim JH, Lee KH, Kim SY, Han SH, Woo JI (2002) Development of the Korean version of the Consortium to Establish a Registry for Alzheimer's Disease Assessment Packet (CERAD-K): clinical and neuropsychological assessment batteries. J Gerontol B Psychol Sci Soc Sci 57:P47-P53.

43. Smith SM, Jenkinson M, Woolrich MW, Beckmann CF, Behrens TE, Johansen-Berg H, Bannister PR, De Luca M, Drobnjak I, Flitney DE, Niazy RK, Saunders J, Vickers J, Zhang Y, De Stefano N, Brady JM, Matthews PM (2004) Advances in functional and structural MR image analysis and implementation as FSL. Neuroimage 23 Suppl 1:S208-S219.

44. Woolrich MW, Jbabdi S, Patenaude B, Chappell M, Makni S, Behrens T, Beckmann C, Jenkinson M, Smith SM (2009) Bayesian analysis of neuroimaging data in FSL. Neuroimage 45(1 Suppl):S173-S186.

45. Visser MM, Yassi N, Campbell BCV, Desmond PM, Davis SM, Spratt N, Parsons M, Bivard A (2019) White matter degeneration after ischemic stroke: a longitudinal diffusion tensor imaging study. J Neuroimaging 29:111-118.

46. Fonov VS, Evans AC, McKinstry RC, Almli CR, Collins DL (2009) Unbiased nonlinear average age-appropriate brain templates from birth to adulthood. NeuroImage 47(Suppl 1):S102.

47. Jenkinson M, Smith S (2001) A global optimisation method for robust affine registration of brain images. Med Image Anal 5:143-156.

48. Jenkinson M, Bannister P, Brady M, Smith S (2002) Improved optimization for the robust and accurate linear registration and motion correction of brain images. Neuroimage 17:825841.

49. Zhang Y, Brady M, Smith S (2001) Segmentation of brain MR images through a hidden Markov random field model and the expectation-maximization algorithm. IEEE Trans Med Imaging 20:45-57.

50. Sotiropoulos SN, Hernández-Fernández M, Vu AT, Andersson JL, Moeller S, Yacoub E, Lenglet C, Ugurbil K, Behrens TEJ, Jbabdi S (2016) Fusion in diffusion MRI for improved fibre orientation estimation: an application to the 3T and 7T data of the Human Connectome Project. Neuroimage
134:396-409.

51. Behrens TE, Berg HJ, Jbabdi S, Rushworth MF, Woolrich MW (2007) Probabilistic diffusion tractography with multiple fibre orientations: what can we gain? Neuroimage 34:144-155.

52. Ostby Y, Tamnes CK, Fjell AM, Westlye LT, Due-Tønnessen P, Walhovd KB (2009) Heterogeneity in subcortical brain development: a structural magnetic resonance imaging study of brain maturation from 8 to 30 years. J Neurosci 29:1177211782.

53. Cordero-Grande L, Christiaens D, Hutter J, Price AN, Hajnal JV (2019) Complex diffusion-weighted image estimation via matrix recovery under general noise models. Neuroimage 200:391-404.

54. Calabrese E, Badea A, Cofer G, Qi Y, Johnson GA (2015) A diffusion MRI tractography connectome of the mouse brain and comparison with neuronal tracer data. Cereb Cortex 25:4628-4637.

55. Nie X, Sun Y, Wan S, Zhao H, Liu R, Li X, Wu S, Nedelska Z, Hort J, Qing Z, Xu Y, Zhang B (2017) Subregional structural alterations in hippocampus and nucleus accumbens correlate with the clinical impairment in patients with Alzheimer's disease clinical spectrum: parallel combining volume and vertex-based approach. Front Neurol 8:399.

56. Okada N, Fukunaga M, Yamashita F, Koshiyama D, Yamamori H, Ohi K, Yasuda Y, Fujimoto M, Watanabe Y, Yahata N, Nemoto K, Hibar DP, van Erp TG, Fujino H, Isobe M, Isomura S, Natsubori T, Narita H, Hashimoto N, Miyata J, Koike S, Takahashi T, Yamasue H, Matsuo K, Onitsuka T, Iidaka T, Kawasaki Y, Yoshimura R, Watanabe Y, Suzuki M, Turner JA, Takeda M, Thompson PM, Ozaki N, Kasai K, Hashimoto R (2016) Abnormal asymmetries in subcortical brain volume in schizophrenia. Mol Psychiatry 21:1460-1466.

57. Sarica A, Vasta R, Novellino F, Vaccaro MG, Cerasa A, Quattrone A; Alzheimer's Disease Neuroimaging Initiative (2018) MRI asymmetry index of hippocampal subfields increases through the continuum from the mild cognitive impairment to the Alzheimer's disease. Front Neurosci 12:576.

58. Pike N (2011) Using false discovery rates for multiple comparisons in ecology and evolution. Methods Ecol Evol 2:278282.

59. Genovese CR, Lazar NA, Nichols T (2002) Thresholding of statistical maps in functional neuroimaging using the false discovery rate. Neuroimage 15:870-878.

60. Chong EY, Huang Y, Wu H, Ghasemzadeh N, Uppal K, Quyyumi AA, Jones DP, Yu T (2015) Local false discovery rate estimation using feature reliability in LC/MS metabolomics data. Sci Rep 5:17221. 
61. Shen X, Reus LM, Cox SR, Adams MJ, Liewald DC, Bastin ME, Smith DJ, Deary IJ, Whalley HC, McIntosh AM (2017) Subcortical volume and white matter integrity abnormalities in major depressive disorder: findings from UK Biobank imaging data. Sci Rep 7:5547.

62. Egger K, Schocke M, Weiss E, Auffinger S, Esterhammer R, Goebel G, Walch T, Mechtcheriakov S, Marksteiner J (2008) Pattern of brain atrophy in elderly patients with depression revealed by voxel-based morphometry. Psychiatry Res 164:237-244.

63. Yamamoto M, Wada-Isoe K, Yamashita F, Nakashita S, Kishi M, Tanaka K, Yamawaki M, Nakashima K (2017) Association between exercise habits and subcortical gray matter volumes in healthy elderly people: a population-based study in Japan. eNeurologicalSci 7:1-6.

64. Zhou H, Li R, Ma Z, Rossi S, Zhu X, Li J (2016) Smaller gray matter volume of hippocampus/parahippocampus in elderly people with subthreshold depression: a cross-sectional study. BMC Psychiatry 16:219.

65. Grimm S, Beck J, Schuepbach D, Hell D, Boesiger P, Bermpohl F, Niehaus L, Boeker H, Northoff G (2008) Imbalance between left and right dorsolateral prefrontal cortex in major depression is linked to negative emotional judgment: an fMRI study in severe major depressive disorder. Biol Psychiatry 63:369-376.

66. Haller S, Borgwardt SJ, Schindler C, Aston J, Radue EW, Riecher-Rössler A (2009) Can cortical thickness asymmetry analysis contribute to detection of at-risk mental state and first-episode psychosis? A pilot study. Radiology 250:212-221.

67. Im SJ, Shim JH, Kim JY, Baek HM (2020) Comparison of differences in brain structure between teenagers and twenties brain using 3 T magnetic resonance imaging. Appl Magn Reson 51:255-276.

68. Cacciola A, Calamuneri A, Milardi D, Mormina E, Chillemi G, Marino S, Naro A, Rizzo G, Anastasi G, Quartarone A (2017) A connectomic analysis of the human basal ganglia network. Front Neuroanat 11:85.

69. Gutman DA, Holtzheimer PE, Behrens TE, Johansen-Berg H, Mayberg HS (2009) A tractography analysis of two deep brain stimulation white matter targets for depression. Biol Psychiatry 65:276-282.

70. Ghaziri J, Tucholka A, Girard G, Boucher O, Houde JC, Descoteaux M, Obaid S, Gilbert G, Rouleau I, Nguyen DK (2018) Subcortical structural connectivity of insular subregions. Sci Rep 8:8596.

71. Heshmati M, Russo SJ (2015) Anhedonia and the brain reward circuitry in depression. Curr Behav Neurosci Rep
2:146-153.

72. Bagot RC, Parise EM, Peña CJ, Zhang HX, Maze I, Chaudhury D, Persaud B, Cachope R, Bolaños-Guzmán CA, Cheer JF, Deisseroth K, Han MH, Nestler EJ (2015) Ventral hippocampal afferents to the nucleus accumbens regulate susceptibility to depression. Nat Commun 6:7062.

73. Hannestad J, Taylor WD, McQuoid DR, Payne ME, Krishnan KR, Steffens DC, Macfall JR (2006) White matter lesion volumes and caudate volumes in late-life depression. Int J Geriatr Psychiatry 21:1193-1198.

74. Admon R, Nickerson LD, Dillon DG, Holmes AJ, Bogdan R, Kumar P, Dougherty DD, Iosifescu DV, Mischoulon D, Fava M, Pizzagalli DA (2015) Dissociable cortico-striatal connectivity abnormalities in major depression in response to monetary gains and penalties. Psychol Med 45:121-131.

75. Davey CG, Harrison BJ, Yücel M, Allen NB (2012) Regionally specific alterations in functional connectivity of the anterior cingulate cortex in major depressive disorder. Psychol Med 42:2071-2081.

76. van Bussel FC, Backes WH, Hofman PA, van Boxtel MP, Schram MT, Stehouwer CD, Wildberger JE, Jansen JF (2016) Altered hippocampal white matter connectivity in type 2 diabetes mellitus and memory decrements. J Neuroendocrinol 28:12366.

77. Choi K, Bagen L, Robinson L, Umbach G, Rugg M, Lega B (2020) Longitudinal differences in human hippocampal connectivity during episodic memory processing. Cereb Cortex Commun 1:tgaa010.

78. Miskowiak KW, Forman JL, Vinberg M, Siebner HR, Kessing LV, Macoveanu J (2020) Impact of pretreatment interhemispheric hippocampal asymmetry on improvement in verbal learning following erythropoietin treatment in mood disorders: a randomized controlled trial. J Psychiatry Neurosci 45:198-205.

79. Demeter S, Rosene DL, Van Hoesen GW (1985) Interhemispheric pathways of the hippocampal formation, presubiculum, and entorhinal and posterior parahippocampal cortices in the rhesus monkey: the structure and organization of the hippocampal commissures. J Comp Neurol 233:30-47.

80. Li SJ, Li Z, Wu G, Zhang MJ, Franczak M, Antuono PG (2002) Alzheimer disease: evaluation of a functional MR imaging index as a marker. Radiology 225:253-259.

81. Manno FAM, Isla AG, Manno SHC, Ahmed I, Cheng SH, Barrios FA, Lau C (2019) Early stage alterations in white matter and decreased functional interhemispheric hippocampal connectivity in the 3xTg mouse model of Alzheimer's disease. Front Aging Neurosci 11:39. 
82. Wang L, Negreira A, LaViolette P, Bakkour A, Sperling RA, Dickerson BC (2010) Intrinsic interhemispheric hippocampal functional connectivity predicts individual differences in memory performance ability. Hippocampus 20:345-351.

83. Ikuta T, Loprinzi PD (2019) Association of cardiorespiratory fitness on interhemispheric hippocampal and parahippocampal functional connectivity. Eur J Neurosci 50:1871-1877.

84. Marquez de la Plata CD, Garces J, Shokri Kojori E, Grinnan J, Krishnan K, Pidikiti R, Spence J, Devous MD Sr, Moore C, McColl R, Madden C, Diaz-Arrastia R (2011) Deficits in functional connectivity of hippocampal and frontal lobe circuits after traumatic axonal injury. Arch Neurol 68:74-84.

85. Postans M, Parker GD, Lundell H, Ptito M, Hamandi K, Gray WP, Aggleton JP, Dyrby TB, Jones DK, Winter M (2020) Uncovering a role for the dorsal hippocampal commissure in recognition memory. Cereb Cortex 30:1001-1015.

86. Ghaziri J, Tucholka A, Girard G, Boucher O, Houde JC, Descoteaux M, Obaid S, Gilbert G, Rouleau I, Nguyen DK (2018) Subcortical structural connectivity of insular subregions. Sci Rep 8:8596.

87. Liao Y, Huang X, Wu Q, Yang C, Kuang W, Du M, Lui S, Yue Q, Chan RC, Kemp GJ, Gong Q (2013) Is depression a disconnection syndrome? Meta-analysis of diffusion tensor imaging studies in patients with MDD. J Psychiatry Neurosci 38:4956.

88. Ma Y (2015) Neuropsychological mechanism underlying antidepressant effect: a systematic meta-analysis. Mol Psychiatry 20:311-319.

89. Cobb JA, Simpson J, Mahajan GJ, Overholser JC, Jurjus GJ, Dieter L, Herbst N, May W, Rajkowska G, Stockmeier CA (2013) Hippocampal volume and total cell numbers in major depressive disorder. J Psychiatr Res 47:299-306.

90. Valdés-Baizabal C, Carbajal GV, Pérez-González D, Malmierca MS (2020) Dopamine modulates subcortical responses to surprising sounds. PLoS Biol 18:e3000744.

91. Kesby JP, Eyles DW, McGrath JJ, Scott JG (2018) Dopamine, psychosis and schizophrenia: the widening gap between basic and clinical neuroscience. Transl Psychiatry 8:30.

92. Martino M, Magioncalda P, Conio B, Capobianco L, Russo D, Adavastro G, Tumati S, Tan Z, Lee HC, Lane TJ, Amore M, Inglese M, Northoff G (2020) Abnormal functional relationship of sensorimotor network with neurotransmitter-related nuclei via subcortical-cortical loops in manic and depressive phases of bipolar disorder. Schizophr Bull 46:163-174.

93. Yan C, Gong G, Wang J, Wang D, Liu D, Zhu C, Chen ZJ, Evans A, Zang Y, He Y (2011) Sex- and brain size-related smallworld structural cortical networks in young adults: a DTI tractography study. Cereb Cortex 21:449-458.

94. Lim S, Han CE, Uhlhaas PJ, Kaiser M (2015) Preferential detachment during human brain development: age- and sexspecific structural connectivity in diffusion tensor imaging (DTI) data. Cereb Cortex 25:1477-1489.

95. Alloza C, Cox SR, Blesa Cábez M, Redmond P, Whalley HC, Ritchie SJ, Muñoz Maniega S, Valdés Hernández MDC, Tucker-Drob EM, Lawrie SM, Wardlaw JM, Deary IJ, Bastin ME (2018) Polygenic risk score for schizophrenia and structural brain connectivity in older age: a longitudinal connectome and tractography study. Neuroimage 183:884-896.

96. Blazer D, Burchett B, Service C, George LK (1991) The association of age and depression among the elderly: an epidemiologic exploration. J Gerontol 46:M210-M215.

97. Pourhoseingholi MA, Baghestani AR, Vahedi M (2012) How to control confounding effects by statistical analysis. Gastroenterol Hepatol Bed Bench 5:79-83.

98. Skelly AC, Dettori JR, Brodt ED (2012) Assessing bias: the importance of considering confounding. Evid Based Spine Care J 3:9-12. 